Article

\title{
Green Synthesis of Magnetite-Based Catalysts for Solar-Assisted Catalytic Wet Peroxide Oxidation
}

\author{
Jorge López (D), Ana Rey (D), Juan F. García-Araya and Pedro M. Álvarez *
}

Citation: López, J.; Rey, A.; García-Araya, J.F.; Álvarez, P.M. Green Synthesis of Magnetite-Based Catalysts for Solar-Assisted Catalytic Wet Peroxide Oxidation. Catalysts 2022, 12, 271. https://doi.org/ $10.3390 /$ catal12030271

Academic Editor:

Hideyuki Katsumata

Received: 17 January 2022

Accepted: 25 February 2022

Published: 28 February 2022

Publisher's Note: MDPI stays neutral with regard to jurisdictional claims in published maps and institutional affiliations.

Copyright: (C) 2022 by the authors. Licensee MDPI, Basel, Switzerland. This article is an open access article distributed under the terms and conditions of the Creative Commons Attribution (CC BY) license (https:// creativecommons.org/licenses/by/ $4.0 /$ )
Departamento de Ingeniería Química y Química Física, Instituto Universitario de Investigación del Agua, Cambio Climático y Sostenibilidad (IACYS), Universidad de Extremadura, 06006 Badajoz, Spain; jorgelg@unex.es (J.L.); anarey@unex.es (A.R.); jfgarcia@unex.es (J.F.G.-A.)

* Correspondence: pmalvare@unex.es

\begin{abstract}
A novel synthesis method under green philosophy for the preparation of some magnetitebased catalysts (MBCs) is presented. The synthesis was carried out in aqueous media (i.e., absence of organic solvents) at room temperature with recovery of excess reactants. Terephthalic acid $\left(\mathrm{H}_{2} \mathrm{BDC}\right)$ was used to drive the synthesis route towards magnetite. Accordingly, bare magnetite $\left(\mathrm{Fe}_{3} \mathrm{O}_{4}\right)$ and some hybrid magnetite-carbon composites were prepared $\left(\mathrm{Fe}_{3} \mathrm{O}_{4}-\mathrm{G}, \mathrm{Fe}_{3} \mathrm{O}_{4}-\mathrm{GO}\right.$, and $\mathrm{Fe}_{3} \mathrm{O}_{4}-\mathrm{AC}$ ). Graphene $(\mathrm{G})$, graphene oxide $(\mathrm{GO})$, and activated carbon $(\mathrm{AC})$ were used as starting carbon materials. The recovered $\mathrm{H}_{2} \mathrm{BDC}$ and the as-synthetized MBCs were fully characterized by XRD, FTIR, Raman spectroscopy, XPS, SQUID magnetometry, TGA-DTA-MS, elemental analysis, and $\mathrm{N}_{2}$-adsorptiondesorption isotherms. The recovered $\mathrm{H}_{2} \mathrm{BDC}$ was of purity high enough to be reused in the synthesis of MBCs. All the catalysts obtained presented the typical crystalline phase of magnetite nanoparticles, moderate surface area (63-337 $\left.\mathrm{m}^{2} \mathrm{~g}^{-1}\right)$, and magnetic properties that allowed their easy separation from aqueous media by an external magnet (magnetization saturation $=25-80 \mathrm{emu} \mathrm{g}^{-1}$ ). The MBCs were tested in catalytic wet peroxide oxidation (CWPO) of an aqueous solution of metoprolol tartrate (MTP) under simulated solar radiation. The $\mathrm{Fe}_{3} \mathrm{O}_{4}-\mathrm{AC}$ materials showed the best catalytic performance among the prepared MBCs, with MTP and total organic carbon (TOC) removals higher than $90 \%$ and $20 \%$, respectively, after $3 \mathrm{~h}$ of treatment. This catalyst was fairly successfully reused in nine consecutive runs, though minor loss of activity was observed, likely due to the accumulation of organic compounds on the porous structure of the activated carbon and/or partial oxidation of surface $\mathrm{Fe}^{2+}$ sites.
\end{abstract}

Keywords: activated carbon; catalytic wet peroxide oxidation; graphene; graphene oxide; green chemistry; magnetite; water treatment

\section{Introduction}

Magnetite-based nanoparticles (NPs) find many applications in several areas such as biomedicine [1-3] and catalysis [4]. Taking advantage of their magnetic properties that allow easy, fast, and cost-effective recovery from the reaction medium, together with their chemical stability, low toxicity, and relatively low cost, a number of magnetite-based catalysts (MBCs) have been proposed to degrade aqueous organic pollutants by different advanced oxidation processes (AOPs) [5]. AOPs are chemical or photochemical processes that trigger the formation of short-lived reactive species (notably hydroxyl radicals, $\mathrm{HO}^{\bullet}$ ) able to degrade water pollutants. By far, since 2008, the most studied AOPs using MBCs have been heterogeneous Fenton and photo-Fenton processes, also called catalytic wet peroxide oxidation (CWPO) [6,7]. Although the mechanism of $\mathrm{H}_{2} \mathrm{O}_{2}$ decomposition over magnetite $\left(\mathrm{Fe}_{3} \mathrm{O}_{4}\right)$ has not been fully elucidated yet, there is general agreement that surface $\equiv \mathrm{Fe}^{2+}$ provokes the decomposition of $\mathrm{H}_{2} \mathrm{O}_{2}$ into $\mathrm{HO}^{\bullet}$ [6-8]. Regeneration of surface $\equiv \mathrm{Fe}^{2+}$ is typically the limiting step that controls the overall process efficiency. When radiation is applied (i.e., heterogeneous photo-Fenton process), the reduction rate of $\equiv \mathrm{Fe}^{3+}$ 
is favored, increasing the formation rate of $\mathrm{HO} \mathrm{O}^{\bullet}$ [7]. To enhance the catalytic properties of bare magnetite in CWPO reactions, several solids have been used to prepare supported or composite materials [6]. Among them, some carbon materials (e.g., activated carbon, biochar, carbon nanotubes, graphene, graphene oxide, or graphitic carbon nitride) have been investigated because of their high surface area and surface chemistry properties $[7,8]$. In addition to providing a greater surface area, favoring the dispersion of magnetite, and increasing the adsorption of organic contaminants, carbon structures may promote electron injection towards magnetite, thus enhancing the regeneration of $\equiv \mathrm{Fe}^{2+}$ sites. Moreover, some carbon materials exhibit catalytic activity in CWPO by themselves [8].

Magnetite can be found in natural minerals or be artificially synthetized [6,7,9]. Synthesis methods are preferred in catalysis to obtain tailored magnetite and MBCs meeting specific properties such as surface area, porosity, particle size, or morphology. The most common synthesis procedures followed to prepare magnetic iron oxide NPs are solgel [10], hydrothermal or solvothermal reactions [11,12], thermal decomposition [13-16], and co-precipitation [17-20]. Similarly, magnetite-carbon composites are obtained by coprecipitation and hydrothermal and sol-gel syntheses [5]. Temperatures around $80-90{ }^{\circ} \mathrm{C}$ were applied to prepare graphene or activated carbon composites by co-precipitation [21,22], whereas a $\mathrm{N}_{2}$ stream at $90^{\circ} \mathrm{C}$ was needed to prepare magnetic activated carbon composites by precipitation [23]. Magnetic activated carbon composites have also been prepared by activation of biowaste in the presence of iron salts in $\mathrm{N}_{2}$ atmosphere and at temperatures as high as $400-800^{\circ} \mathrm{C}$ [24]. Generally, all these methods involve the use of organic solvents, moderate to high temperatures, and/or chemical reagents (e.g., $\mathrm{H}_{2} \mathrm{O}_{2}, \mathrm{NaNO}_{2}$, and $\mathrm{Na}_{2} \mathrm{SO}_{3}$ ). Even a more environmentally friendly method reported for the synthesis of magnetite NPs using vegetable extracts required moderate temperature (i.e., $80^{\circ} \mathrm{C}$ ) [25]. Therefore, the search for more sustainable and economic synthesis methods for MBCs is required to overcome the hurdle for the scale-up and optimization of processes catalyzed by these materials $[26,27]$.

This work presented a novel, environmentally friendly synthesis method of MBCs based on a terephthalate intermediate as structure director. Green chemistry philosophy towards circular use of resources was applied with an almost full recovery of the synthesis mediator, terephthalic acid $\left(\mathrm{H}_{2} \mathrm{BDC}\right)$. The method was successfully used to prepare bare magnetite and different carbon-magnetite composites with activated carbon, graphene, and graphene oxide. Herein, fully characterization of the prepared MBCs and their use as catalysts in solar assisted-CWPO of aqueous solution of the drug metoprolol tartrate (MTP) were reported. Emphasis was placed on catalyst stability, separability, recovery, and reusability.

\section{Results and Discussion}

\subsection{Synthesis of $M B C S$}

Table 1 shows main conditions used for MBCs synthesis, mass yield (i.e., ratio of solid obtained with respect to its theoretical weight), and percentage of terephthalic acid recovered after the synthesis. In Table 1, G stands for graphene nanoplatelets, GO for graphene oxide, and $\mathrm{AC}$ for activated carbon. Subscript $\mathrm{R}$ refers to both recovered $\mathrm{H}_{2} \mathrm{BDC}$ in each batch synthesis and a $\mathrm{MBC}$ sample $\left(\mathrm{Fe}_{3} \mathrm{O}_{4}-\mathrm{AC}\right.$ ) synthetized with $\mathrm{H}_{2} \mathrm{BDC}$ recovered from a previous synthesis batch. Typically, synthesis batches were designed to obtain c.a. $0.4 \mathrm{~g} \mathrm{Fe}_{3} \mathrm{O}_{4}$ in each MBC sample (see Section 3.2). In addition, batches intended to procure higher amounts of catalyst were also carried out for comparative purposes. They are designated with the subscript L (i.e., larger amount). As seen in Table 1, the mass yield observed after the synthesis of most of the MBC samples was near $100 \%$, meaning almost full utilization of the limiting reagent (i.e., iron salt) and carbonaceous support. The lower yield observed for the $\mathrm{Fe}_{3} \mathrm{O}_{4}$-GO composite might be related to the acidic character of GO in aqueous suspension being relatively instable in alkaline solution [28]. The separation of magnetic particles by an external magnet during the washing steps of the synthesis procedure was complete and no turbidity was observed in the washing solution. The 
use of $\mathrm{H}_{2} \mathrm{BDC}$ was crucial for successful synthesis of MBCs. Thus, preliminary tests demonstrated that magnetite was not formed at the conditions given in Table 1 but the absence of terephthalic acid. Therefore, it can be hypothesized that $\mathrm{H}_{2} \mathrm{BDC}$ mediates the generation of magnetite through the formation of a terephthalic intermediate, which favors the oxidation of $\mathrm{Fe}^{2+}$ at alkaline conditions with subsequent precipitation of $\mathrm{Fe}_{3} \mathrm{O}_{4}$ according to the following simplified set of reactions:

$$
\begin{gathered}
3 \mathrm{FeCl}_{2}+3 \mathrm{H}_{2} \mathrm{BDC}+\mathrm{NaOH}_{(\mathrm{ex})} \rightarrow 3\left[\mathrm{Fe}-\mathrm{BDC}^{*}{ }_{(\mathrm{s})}+6 \mathrm{HCl}+\mathrm{NaOH}_{(\mathrm{ex})}\right. \\
3\left[\mathrm{Fe}-\mathrm{BDC}^{*}{ }_{(\mathrm{s})}+\mathrm{OH}^{-}{ }_{(\mathrm{ex})} \rightarrow \mathrm{Fe}_{3} \mathrm{O}_{4(\mathrm{~s})}+3 \mathrm{BDC}^{2-}+\mathrm{OH}^{-}{ }_{(\mathrm{ex})}\right.
\end{gathered}
$$

After separation of the magnetic particles, the aqueous media contained terephthalate (see Reaction (2)) that was almost completely recovered after acidification with $\mathrm{HCl}$ to $\mathrm{pH}<3$ according to:

$$
\mathrm{BDC}^{2-}+\mathrm{HCl}_{(\mathrm{ex})} \rightarrow \mathrm{H}_{2} \mathrm{BDC}_{(\mathrm{s})}+\mathrm{HCl}_{(\mathrm{ex})}
$$

\begin{tabular}{|c|c|c|c|c|c|c|c|c|}
\hline MBC & $\begin{array}{l}\text { Carbon } \\
\text { Mass (g) }\end{array}$ & $\begin{array}{c}\mathrm{V}_{\mathrm{NaOH}} \\
(\mathrm{mL})\end{array}$ & $\mathrm{V}_{\text {Total }}(\mathrm{mL})$ & $\mathrm{H}_{2}$ BDC (g) & $\begin{array}{c}\mathrm{FeCl}_{2} \cdot 4 \mathrm{H}_{2} \mathrm{O} \\
\text { (g) }\end{array}$ & $\mathrm{T}\left({ }^{\circ} \mathrm{C}\right)$ & Yield (\%) & $\begin{array}{c}\left(\mathrm{H}_{2} \mathrm{BDC}_{\mathrm{R}}\right. \\
(\%)\end{array}$ \\
\hline $\mathrm{Fe}_{3} \mathrm{O}_{4}$ & - & 20 & 70 & 0.835 & 1.0 & 20 & 99.9 & 99 \\
\hline $\mathrm{Fe}_{3} \mathrm{O}_{4}-\mathrm{G}$ & 0.3 & 20 & 70 & 0.835 & 1.0 & 20 & 99.5 & 98 \\
\hline $\mathrm{Fe}_{3} \mathrm{O}_{4}-\mathrm{GO}$ & 0.3 & 20 & 70 & 0.835 & 1.0 & 20 & 97.1 & 97 \\
\hline $\mathrm{Fe}_{3} \mathrm{O}_{4}-\mathrm{AC}$ & 0.3 & 20 & 70 & 0.835 & 1.0 & 20 & 99.9 & 96 \\
\hline $\mathrm{Fe}_{3} \mathrm{O}_{4}-\mathrm{AC}_{\mathrm{R}}$ & 0.3 & 20 & 70 & 0.835 & 1.0 & 20 & 99.9 & 96 \\
\hline $\mathrm{Fe}_{3} \mathrm{O}_{4}-\mathrm{AC}_{\mathrm{L}}$ & 6 & 400 & 1400 & 16.7 & 20 & 20 & 99.9 & 96 \\
\hline
\end{tabular}

Table 1. Synthesis conditions, yield, and $\mathrm{H}_{2} \mathrm{BDC}$ recovery in the preparation of some MBCs.

The percentage of $\mathrm{H}_{2} \mathrm{BDC}$ recovered in any synthesis batch was higher than $95 \%$, as shown in Table 1 . The recovered solid was dried and characterized to confirm its purity. Figure 1 shows the X-ray diffraction (XRD) patterns (A) and Fourier-transformed infrared (FTIR) spectra (B) of pure and recovered terephthalic acid. All the diffraction peaks observed are ascribable to triclinic terephthalic acid indexed in the ICCD ${ }^{\circledR}$ (PDF 00-031-1916) with main contributions at 17.4 (110), 25.2 (011), and 27.9 (200) [29]. No other crystalline phases were found in the solid obtained [30]. Moreover, the FTIR spectra of pure $\mathrm{H}_{2} \mathrm{BDC}$ and recovered samples showed similar profiles with matching bands indicating also similar chemical structure. The broad band at $2250-3250 \mathrm{~cm}^{-1}$ can be attributed to stretching vibration of the $-\mathrm{OH}$ (carboxyl group) while other main bands located at 1680, 1575-1420, and $1285 \mathrm{~cm}^{-1}$ can be assigned to stretching vibrations of $-\mathrm{C}=\mathrm{O}$ (carboxylic group), $-\mathrm{C}=\mathrm{C}-$, and $-\mathrm{C}-\mathrm{H}$ bonds (aromatic structure), and $-\mathrm{C}-\mathrm{OH}$ (acid), respectively $[29,31]$. In order to fully characterize the solid recovered $\left(\mathrm{H}_{2} \mathrm{BDC}-\mathrm{R}\right)$, elemental analysis was performed and compared with that of pure terephthalic acid $\left(\mathrm{H}_{2} \mathrm{BDC}-\mathrm{t}\right)$. As shown in Table 2, the percentages of $\mathrm{C}, \mathrm{H}$, and $\mathrm{O}$ found in the recovered solid were very close to the theoretical values of pure $\mathrm{H}_{2} \mathrm{BDC}$. Another proof of the purity of the sample recovered after the synthesis of MBCs was obtained by dissolving the obtained solid in ultrapure water and analyzing the solution by HPLC, resulting in peak integration that did not differ by more than $2 \%$ from the calibration curve obtained with pure $\mathrm{H}_{2} \mathrm{BDC}$. Additionally, the presence of iron compounds in the solid recovered was ruled out after the analysis of iron at ppb level in the aqueous solution prepared in ultrapure water. 

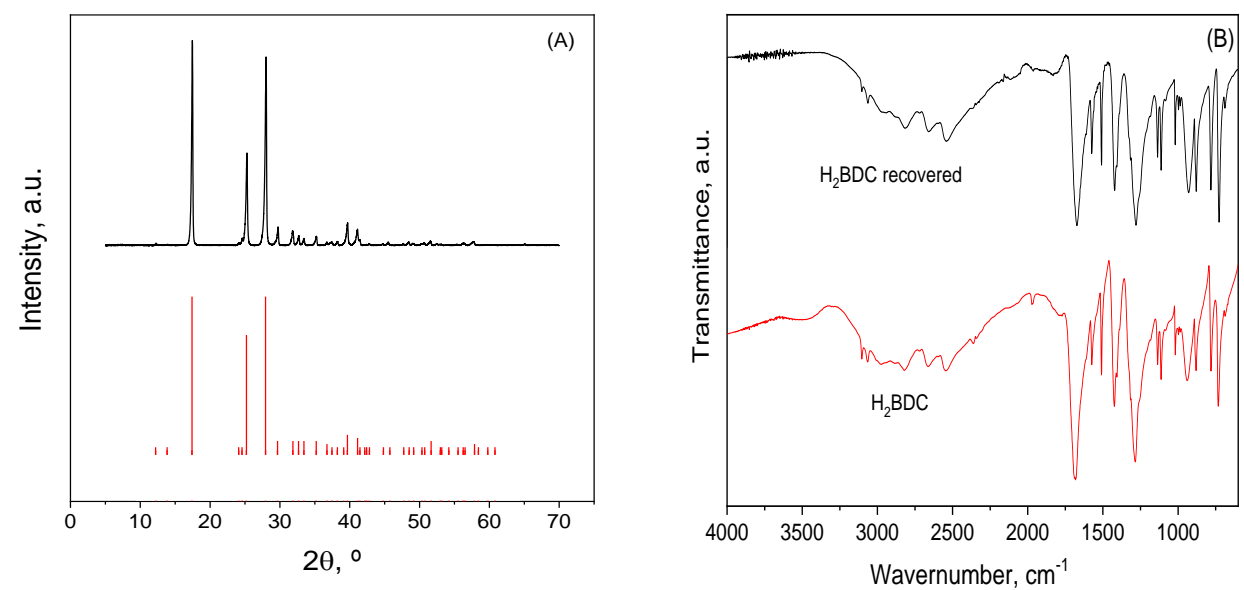

Figure 1. XRD patterns of recovered $\mathrm{H}_{2} \mathrm{BDC}$ and ICCD PDF 00-031-1916 file (A). FTIR spectra of pure and recovered $\mathrm{H}_{2} \mathrm{BDC}(\mathbf{B})$.

Table 2. Elemental analysis of recovered $\mathrm{H}_{2} \mathrm{BDC}$.

\begin{tabular}{ccccc}
\hline Sample & $\mathbf{C}(\mathbf{w t .} \%)$ & H (wt.\%) & N (wt.\%) & O (wt.\%) \\
\hline $\mathrm{H}_{2}$ BDC-t & 57.84 & 3.64 & 0.00 & 38.52 \\
$\mathrm{H}_{2}$ BDC-R & 57.50 & 3.59 & 0.03 & 38.88 \\
\hline
\end{tabular}

All these characterization results pointed out the purity level of the terephthalic acid recovered. Accordingly, some subsequent synthesis batches were performed with the recovered solid and the required amount of make-up pure $\mathrm{H}_{2} \mathrm{BDC}$. As an example, Table 1 shows the $\mathrm{MBC}$ labelled as $\mathrm{Fe}_{3} \mathrm{O}_{4}-\mathrm{AC}$. Both, the mass yield and the percentage of terephthalic recovered were as high as those for its homologous $\mathrm{Fe}_{3} \mathrm{O}_{4}-\mathrm{AC}$ sample obtained with pure commercial $\mathrm{H}_{2} \mathrm{BDC}$ only. Furthermore, characterization results of both $\mathrm{MBC}$ samples were very alike, as demonstrated by techniques shown in Section 2.2.

Another key aspect of the MBCs considered in this work is their easy preparation in large quantities, which eventually would lead to a scalable synthesis. As an example, the synthesis procedure proposed was successfully carried out in $1.4 \mathrm{~L}$ of total volume to obtain $13.7 \mathrm{~g}$ of a $\mathrm{Fe}_{3} \mathrm{O}_{4}-\mathrm{AC}_{\mathrm{L}}$ composite, which featured the same characteristics as its counterpart obtained at lower mass scale. See Table 1 for mass yield $(99.9 \%)$ and terephthalic acid recovery $(96 \%)$ and Section 2.2 for XRD patterns and textural properties of MBC samples.

In summary, the soft experimental conditions, the use of water as a solvent, the low toxicity of the materials used [32-34], and the efficient use of reagents and recovery of terephthalic acid are in clearly line of greener synthesis methods to obtain more environmentally friendly materials to be applied in large-scale processes [35-38].

\subsection{Characterization of $M B C s$}

Elemental analysis $(\mathrm{C}, \mathrm{H}, \mathrm{N})$ of the as-synthetized MBCs is presented in Table 3 together with the percentage of iron (also calculated as wt.\% of $\mathrm{Fe}_{3} \mathrm{O}_{4}$ ), and the percentage of carbon calculated from the amounts of $\mathrm{CO}$ and $\mathrm{CO}_{2}$ detected by TGA-DTA-MS.

The bare iron material prepared (i.e., $\mathrm{Fe}_{3} \mathrm{O}_{4}$ sample) showed a very low carbon content as measured by elemental analysis and TGA-DTA-MS, indicating that most of the terephthalic acid precursor was removed during the washing procedure. This agrees with the high level of terephthalic acid recovered after the synthesis procedure. On the other hand, the carbon-containing MBCs presented carbon percentages that are consistent with their expected carbon content taking into account the relative amounts of carbon in $\mathrm{G}(90 \mathrm{wt} . \%)$, GO (53 wt.\%), and AC (70 wt.\%). Besides, the theoretical iron content of these composites is c.a. 41 wt.\%, which is close to the actual values for $\mathrm{Fe}_{3} \mathrm{O}_{4}-\mathrm{G}$ and $\mathrm{Fe}_{3} \mathrm{O}_{4}-\mathrm{AC}$ samples. However, the $\mathrm{Fe}_{3} \mathrm{O}_{4}$-GO sample exhibited a somewhat higher iron content, which might 
be due to the modification of graphene oxygen groups during the synthesis method. The percentages of carbon in MBC samples were also corroborated by thermogravimetric and differential thermal analysis coupled to mass spectrometry (TGA-DTA-MS). The evolution of overall mass loss and $\mathrm{CO}, \mathrm{CO}_{2}$, and $\mathrm{H}_{2} \mathrm{O}$ released upon heating in air flow are presented in Figure 2. The first mass loss event observed up to $150{ }^{\circ} \mathrm{C}$ can be ascribed to humidity, being more noticeable for the $\mathrm{Fe}_{3} \mathrm{O}_{4}-\mathrm{GO}$ sample. Then, there was another weight loss at 200-300 ${ }^{\circ} \mathrm{C}$ with liberation of $\mathrm{H}_{2} \mathrm{O}, \mathrm{CO}$, and $\mathrm{CO}_{2}$ that could be attributable to the decomposition of labile surface oxygen groups from the carbonaceous structure like carboxylic acids, with a greater presence in the GO material $[39,40]$. At higher temperatures, desorption of more stable oxygen groups and oxidation of the carbon materials takes place. The residue remaining after the TG analysis would most likely be composed of completely oxidized iron and ashes from carbonaceous materials (mostly in AC support).

Table 3. Elemental analysis, WDXRF, and TG results of some MBCs.

\begin{tabular}{ccccccc}
\hline & \multicolumn{3}{c}{ Elemental Analysis } & & WDXRF & $\begin{array}{c}\text { TGA- } \\
\text { DTA-MS }\end{array}$ \\
\hline MBC & $\mathbf{C}($ wt.\%) & H (wt.\%) & $\mathbf{N ~ ( w t . \% ) ~}$ & Fe (wt.\%) & $\begin{array}{c}\mathbf{F e}_{3} \mathbf{O}_{4} \\
(\mathbf{w t .} \%)\end{array}$ & $\mathbf{C}$ (wt.\%) \\
\hline $\mathrm{Fe}_{3} \mathrm{O}_{4}$ & 0.73 & 0.00 & 0.00 & 72.36 & 100.00 & $<0.5$ \\
$\mathrm{Fe}_{3} \mathrm{O}_{4}-\mathrm{G}$ & 37.00 & 0.47 & 0.11 & 44.89 & 62.04 & 38.55 \\
$\mathrm{Fe}_{3} \mathrm{O}_{4}-\mathrm{GO}$ & 22.00 & 0.91 & 0.00 & 55.28 & 76.40 & 23.22 \\
$\mathrm{Fe}_{3} \mathrm{O}_{4}-\mathrm{AC}$ & 32.00 & 0.71 & 0.21 & 45.85 & 63.36 & 34.25 \\
\hline
\end{tabular}
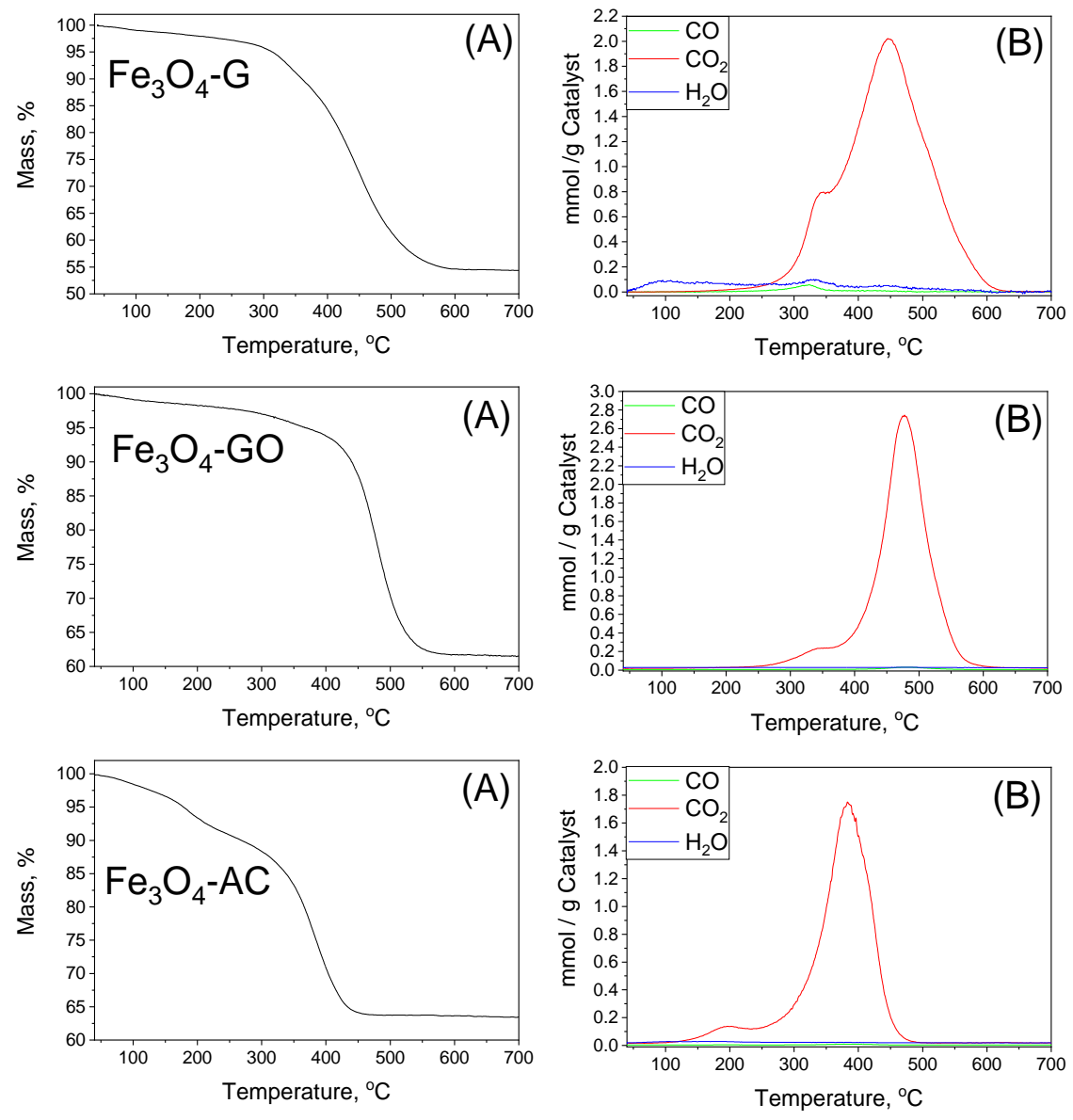

Figure 2. TGA-DTA-MS in air: (A) mass loss, and (B) gases released. 
At this point, it should be mentioned that the presence of minor amounts of residual terephthalic acid in MBC samples cannot be discarded. Sublimation of terephthalic acid took place as an endothermic process at $300-400{ }^{\circ} \mathrm{C}$ according with the TGA-DTA of pure $\mathrm{H}_{2} \mathrm{BDC}$ (Figure 3 ) in which neither $\mathrm{CO}_{2}$ nor $\mathrm{CO}$ were detected.

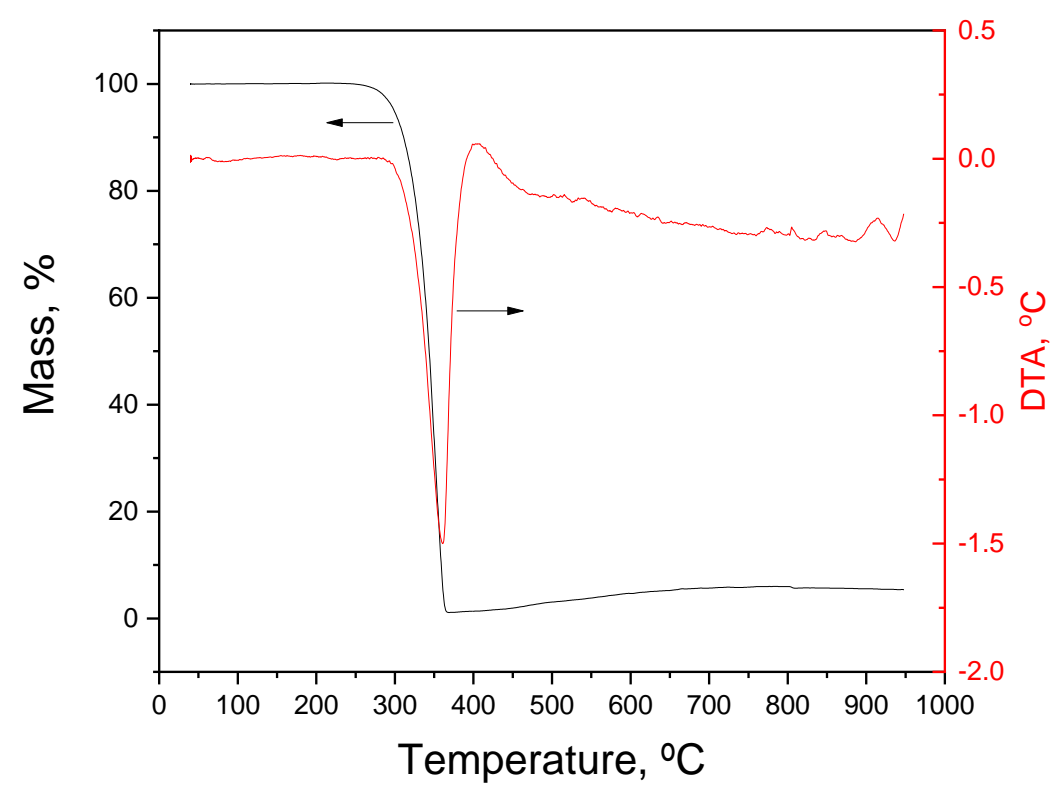

Figure 3. TGA-DTA of terephthalic acid in air.

Regarding the crystalline structure of MBC samples, Figure 4 shows the XRD patterns (A) and Raman spectra (B) of some as-synthetized materials. The main reflection peaks observed in XRD at $2 \theta 30.2^{\circ}, 35.5^{\circ}, 43.2^{\circ}, 53.6^{\circ}, 57.1^{\circ}$, and $62.7^{\circ}$ are fully ascribable to the cubic structure of magnetite according to PDF 01-075-0449 pattern file of the ICCD ${ }^{\circledR}$. The presence of other iron species like maghemite would be evidenced by two additional peaks at $23.8^{\circ}$ and $26.1^{\circ}$ that do not appear in the patterns of Figure 4A [41]. Thus, although the presence of maghemite in the samples cannot be fully discarded, its content would be negligible. The XRD patterns also pointed out that the $\mathrm{Fe}_{3} \mathrm{O}_{4}-\mathrm{GO}$ sample presented the lowest crystallinity among the prepared MBCs with wider peaks even having a high percentage of iron. The crystallite size of magnetite in the materials was determined by the Scherrer's equation from the (311) diffraction peak at $35.5^{\circ}$ and the values obtained are shown in Figure 4A. As seen, they ranged from $20.1 \mathrm{~nm}$ for $\mathrm{Fe}_{3} \mathrm{O}_{4}-\mathrm{GO}$ to $29.8 \mathrm{~nm}$ for $\mathrm{Fe}_{3} \mathrm{O}_{4}$ and $\mathrm{Fe}_{3} \mathrm{O}_{4}-\mathrm{G}$ samples.

The Raman spectrum of the $\mathrm{Fe}_{3} \mathrm{O}_{4}$ sample showed their typical bands of magnetite at $630-660 \mathrm{~cm}^{-1}$ with a broad band around $1300 \mathrm{~cm}^{-1}$, also ascribable to a second-order peak of magnetite-like materials. Besides, traces of other iron oxide and hydroxide phases were deduced by the presence of the peaks at 219, 281, and $398 \mathrm{~cm}^{-1}$. Nevertheless, it should be kept in mind that the formation of these structures by oxidation during Raman analyses due to the heating of the laser beam cannot be discarded [42]. In addition to these bands related to iron species, the spectra of carbon-containing MBCs showed carbon D and G bands at 1309 and $1595 \mathrm{~cm}^{-1}$ respectively. Typically, the intensity ratio ID/IG from the areas of the corresponding bands are related to the frequency of defects in different carbon materials. In this case, the presence of the magnetite band at $1300 \mathrm{~cm}^{-1}$ overlapped with the D contribution, making the ID/IG ratio quantification difficult. Nonetheless, it can be easily noticed that the spectrum of the $\mathrm{Fe}_{3} \mathrm{O}_{4}-\mathrm{G}$ sample exhibited higher intensity of the $\mathrm{G}$ band, due to multi-layer arrangement, and the presence of the $2 \mathrm{D}$ band at $2646 \mathrm{~cm}^{-1}$ [40]. 



Figure 4. XRD patterns (A) and Raman spectra (B) of the as-synthetized MBCs.

FTIR spectra of MBC samples is presented in Figure 5. This characterization technique might help discriminate between magnetite and maghemite. The intense band located at $570 \mathrm{~cm}^{-1}$ is ascribable to Fe-O-Fe from magnetite while the broad shoulder up to $750 \mathrm{~cm}^{-1}$ can be assigned to partially oxidized magnetite on the surface, with a stoichiometry approaching maghemite $[43,44]$. On the other hand, the bands located at $640 \mathrm{~cm}^{-1}$ and $725 \mathrm{~cm}^{-1}$, clearly visible in the spectra of $\mathrm{Fe}_{3} \mathrm{O}_{4}-\mathrm{G}$ and $\mathrm{Fe}_{3} \mathrm{O}_{4}$-GO samples but very subtle in that of $\mathrm{Fe}_{3} \mathrm{O}_{4}-\mathrm{AC}$, suggest the presence of maghemite in the surface to some extent. In any case, the relative intensity of these IR bands and the findings from XRD results point out a minor contribution of maghemite to total iron oxide content in the synthetized samples. No important peaks were observed in the region between $2000-1000 \mathrm{~cm}^{-1}$ of the FTIR spectrum of the $\mathrm{Fe}_{3} \mathrm{O}_{4}$ sample, which indicates the lack of organic compounds on the surface [45]. Then, residual $\mathrm{H}_{2} \mathrm{BDC}$ remaining in the catalyst after the synthesis was expected to be of low significance. On the other hand, for the carbon composites the visible bands in the same wavenumber range can be most likely ascribed to different surface oxygen groups in the carbon structures, which are less abundant in the graphene composite [46,47]. Nevertheless, the presence of minor amounts of residual $\mathrm{H}_{2} \mathrm{BDC}$ in carbon MBCs, which was revealed in stability tests (see Section 2.3), is also consistent with FTIR results.

Magnetization hysteresis loops of some MBC samples are plotted in Figure 6, where it can be seen that saturation magnetization $\left(\mathrm{M}_{\mathrm{S}}\right)$ ranged from $25.6 \mathrm{emu} \mathrm{g}{ }^{-1}\left(\mathrm{Fe}_{3} \mathrm{O}_{4}-\mathrm{GO}\right)$ to $80.6 \mathrm{emu} \mathrm{g}^{-1}\left(\mathrm{Fe}_{3} \mathrm{O}_{4}\right)$. This latter value is in the typical range of magnetite NPs, which exhibit saturation magnetization from 60 to $90 \mathrm{emu} \mathrm{g}^{-1}$ depending on the morphology and particle size. In general, the higher the particle size, the higher the $\mathrm{MS}_{\mathrm{S}}[44,48,49]$. The $\mathrm{Fe}_{3} \mathrm{O}_{4}$ sample synthetized here, with crystal size near $30 \mathrm{~nm}$, showed a saturation magnetization slightly higher than values reported for other magnetite samples with similar particle size [48]. On the other hand, the carbon- $\mathrm{Fe}_{3} \mathrm{O}_{4}$ hybrid materials presented lower saturation magnetization values. While the MS values observed for $\mathrm{Fe}_{3} \mathrm{O}_{4}-\mathrm{G}\left(36.1 \mathrm{emu} \mathrm{g}^{-1}\right)$ and $\mathrm{Fe}_{3} \mathrm{O}_{4}$-AC (38.7 emu g ${ }^{-1}$ ) are consistent with the percentage of iron in these materials as determined by WDXRF (see Table 3), the saturation magnetization of the $\mathrm{Fe}_{3} \mathrm{O}_{4}$-GO composite was somewhat lower despite its higher content of iron. This can be explained by the smaller magnetite crystal size (see Figure $4 \mathrm{~A}$ ) and the possible presence of other iron species to some extent. 

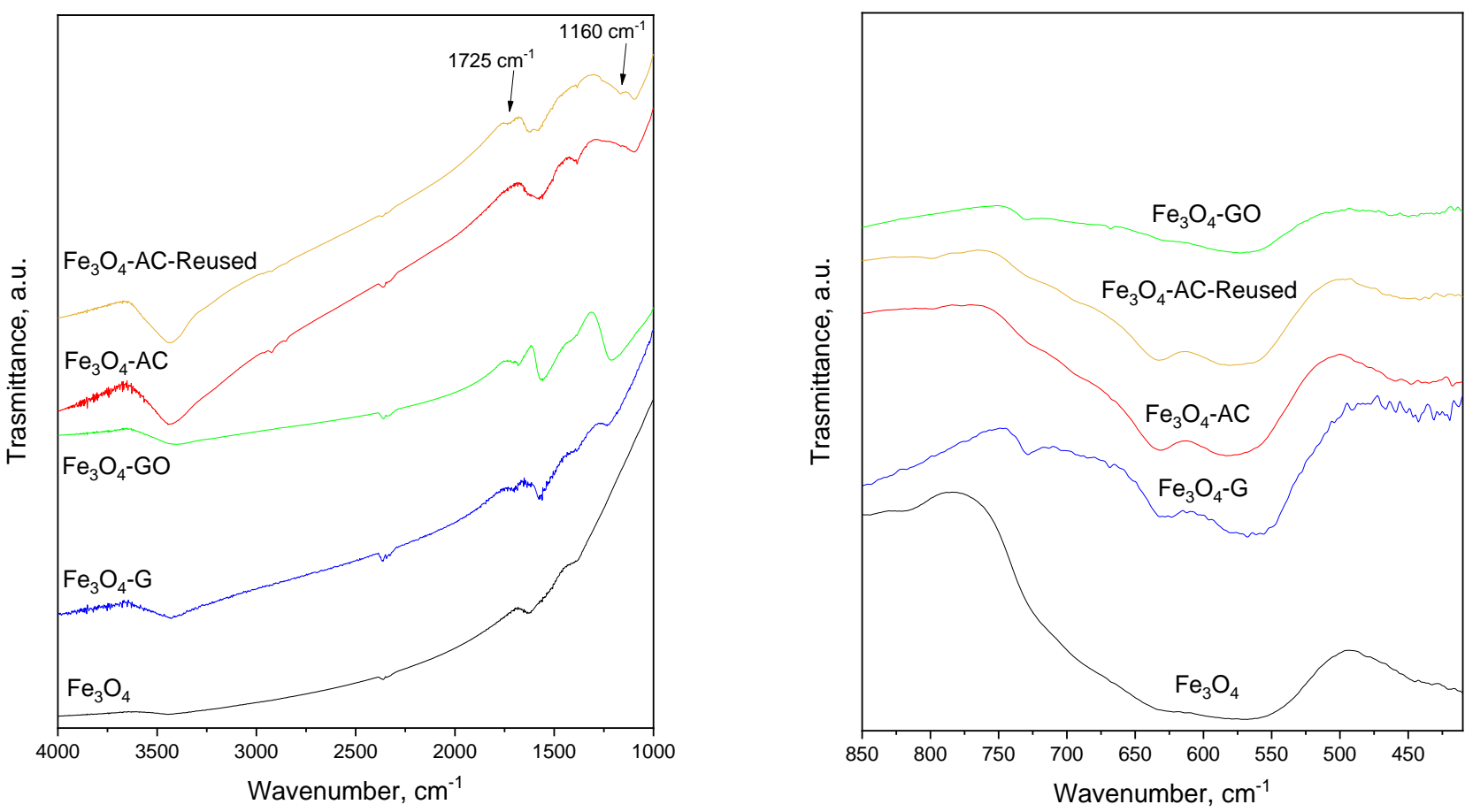

Figure 5. FTIR spectra of the as-synthetized materials.

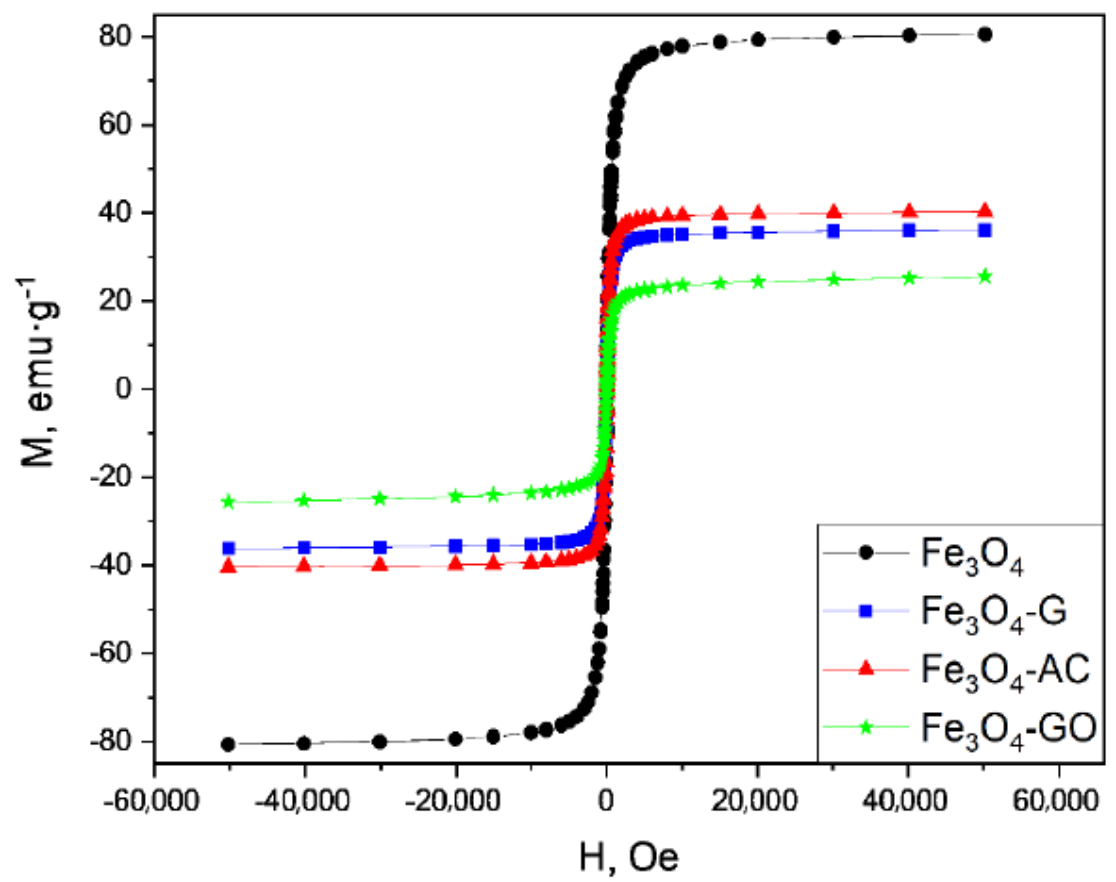

Figure 6. Magnetization vs. applied magnetic field at $25^{\circ} \mathrm{C}$.

Finally, some main textural parameters obtained by $\mathrm{N}_{2}$ adsorption-desorption isotherms plotted in Figure 7 are summarized in Table 4. The results of the carbonaceous materials used as precursors have been added to the table for comparative purposes. First, it is apparent that the $\mathrm{Fe}_{3} \mathrm{O}_{4}$ sample displayed a type IV isotherm with a hysteresis loop typical of mesoporous materials, with a moderate surface area and very low micropore volume. On the other hand, the combination of magnetite with carbonaceous structures led to composites with higher surface areas according to the porous structure of the supports. These results are consistent with other magnetic-carbon composites reported in the literature [50]. 
Then, the largest BET area was obtained for $\mathrm{Fe}_{3} \mathrm{O}_{4}-\mathrm{G}$ followed by $\mathrm{Fe}_{3} \mathrm{O}_{4}-\mathrm{AC}$ and $\mathrm{Fe}_{3} \mathrm{O}_{4}$-GO. The values of surface area observed for $\mathrm{Fe}_{3} \mathrm{O}_{4}-\mathrm{AC}$ and $\mathrm{Fe}_{3} \mathrm{O}_{4}-\mathrm{G}$ samples with respect to their corresponding carbon supports (i.e., AC and G, respectively) were found proportional to the carbon content in the composite material.



Figure 7. $\mathrm{N}_{2}$ adsorption-desorption isotherms.

Table 4. Textural properties of the as-synthetized MBCs and their carbonaceous supports.

\begin{tabular}{|c|c|c|c|c|}
\hline Sample & $\begin{array}{c}\mathrm{S}_{\mathrm{BET}} \\
\left(\mathrm{m}^{2} \mathrm{~g}^{-1}\right)\end{array}$ & $\begin{array}{c}S_{\mathrm{EXT}} \\
\left(\mathrm{m}^{2} \mathrm{~g}^{-1}\right)\end{array}$ & $\begin{array}{l}\mathrm{V}_{\text {MICRO }} \\
\left(\mathrm{cm}^{3} \mathrm{~g}^{-1}\right)\end{array}$ & $\begin{array}{l}\mathrm{V}_{\text {TOTAL }} \\
\left(\mathrm{cm}^{3} \mathrm{~g}^{-1}\right)\end{array}$ \\
\hline G & 760 & 514 & 0.118 & 1.122 \\
\hline GO & 142 & 122 & 0.024 & 0.220 \\
\hline $\mathrm{AC}$ & 644 & 37 & 0.303 & 0.361 \\
\hline $\mathrm{Fe}_{3} \mathrm{O}_{4}$ & 63 & 59 & 0.005 & 0.374 \\
\hline $\mathrm{Fe}_{3} \mathrm{O}_{4}-\mathrm{G}$ & 337 & 271 & 0.048 & 0.764 \\
\hline $\mathrm{Fe}_{3} \mathrm{O}_{4}-\mathrm{GO}$ & 164 & 131 & 0.036 & 0.353 \\
\hline $\mathrm{Fe}_{3} \mathrm{O}_{4}-\mathrm{AC}$ & 282 & 213 & 0.052 & 0.578 \\
\hline $\mathrm{Fe}_{3} \mathrm{O}_{4}-\mathrm{AC}-\mathrm{L}$ & 240 & 181 & 0.029 & 0.641 \\
\hline $\mathrm{Fe}_{3} \mathrm{O}_{4}$-AC-Reused & 255 & 255 & 0.001 & 0.801 \\
\hline
\end{tabular}

\subsection{Stability of $M B C$ s in Water}

The stability of the as-synthetized materials in water was studied at different conditions. First, long-term runs were carried out for 7 days in ultrapure water buffered solution at MBC concentration of $1 \mathrm{~g} \mathrm{~L}^{-1}$. Table 5 summarizes data of $\mathrm{pH}$, concentration of $\mathrm{H}_{2} \mathrm{BDC}$, $\mathrm{Fe}$, and total organic carbon (TOC) after some experiments. Regardless of the $\mathrm{pH}$, the concentration of $\mathrm{H}_{2} \mathrm{BDC}$ in solution after the runs carried out with the $\mathrm{Fe}_{3} \mathrm{O}_{4}$ sample was only about $1 \mathrm{mg} \mathrm{L}^{-1}$, which agrees with a small presence of residual terephthalate in the catalyst after the synthesis procedure (see FTIR results). On the other hand, the values of $\mathrm{H}_{2} \mathrm{BDC}$ in solution observed when carbon MBCs were brought into contact with water were significantly larger and they increased with the aqueous $\mathrm{pH}$. This suggests that some amount of $\mathrm{H}_{2} \mathrm{BDC}$ adsorbed onto the carbonaceous materials can be favourably desorbed at alkaline conditions. If results of $\mathrm{H}_{2} \mathrm{BDC}$ recovery shown in Table 1 are considered, the maxima concentration of $\mathrm{H}_{2} \mathrm{BDC}$ observed after stability tests (i.e., at $\mathrm{pH}=8-10$ ) accounted for $78 \%, 62 \%$, and $42 \%$ of the maximum releasable $\mathrm{H}_{2} \mathrm{BDC}$ from $\mathrm{Fe}_{3} \mathrm{O}_{4}-\mathrm{G}, \mathrm{Fe}_{3} \mathrm{O}_{4}-\mathrm{GO}$, and $\mathrm{Fe}_{3} \mathrm{O}_{4}-\mathrm{AC}$, respectively. This proves alkaline desorption as a good alternative to remove 
residual $\mathrm{H}_{2} \mathrm{BDC}$ from the catalysts. Then, a sample of $\mathrm{Fe}_{3} \mathrm{O}_{4}-\mathrm{AC}$ was subjected to an additional washing step in $\mathrm{NaOH}$ solution $(\mathrm{pH} 10)$ and used in catalytic activity tests for comparative purposes (see Section 2.4).

Table 5. Results from MBCs long-term stability tests at different $\mathrm{pH}$.

\begin{tabular}{|c|c|c|c|c|c|c|c|}
\hline MBC & $\mathrm{pH}_{0}$ & $\mathrm{pH}_{\mathrm{f}}$ & $\mathrm{H}_{2} \mathrm{BDC}\left(\mathrm{mg} \mathrm{L}^{-1}\right)$ & $\begin{array}{c}\text { TOC }_{\text {H2BDC }} \\
\left(\mathrm{mg} \mathrm{L}^{-1}\right)\end{array}$ & $\begin{array}{c}\text { TOC } \\
\left(\mathrm{mg} \mathrm{L}^{-1}\right)\end{array}$ & $\begin{array}{l}\text { (1) } \text { Diff }_{\text {TOC }} \\
\left(\mathrm{mg} \mathrm{L}^{-1}\right)\end{array}$ & $\begin{array}{c}\text { (2) } \mathrm{Fe} \\
\left(\mathrm{mg} \mathrm{L}^{-1}\right)\end{array}$ \\
\hline \multirow{5}{*}{$\mathrm{Fe}_{3} \mathrm{O}_{4}$} & 4.00 & 4.61 & 0.93 & 0.54 & 0.92 & 0.38 & $0.18 / 0.12$ \\
\hline & 6.00 & 6.13 & 1.04 & 0.60 & 0.58 & -0.02 & $0.37 / 0.28$ \\
\hline & 7.00 & 7.06 & 0.91 & 0.53 & 1.10 & 0.58 & $0.99 / 0.16$ \\
\hline & 8.00 & 7.96 & 0.98 & 0.57 & 0.81 & 0.24 & $1.34 / 0.26$ \\
\hline & 10.00 & 9.73 & 1.02 & 0.59 & 1.20 & 0.61 & $1.69 / 0.11$ \\
\hline \multirow{5}{*}{$\mathrm{Fe}_{3} \mathrm{O}_{4}-\mathrm{G}$} & 4.00 & 4.45 & 8.22 & 4.75 & 5.16 & 0.41 & $0.19 / 0.17$ \\
\hline & 6.00 & 6.01 & 27.01 & 15.61 & 15.79 & 0.18 & $0.39 / 0.10$ \\
\hline & 7.00 & 6.93 & 31.53 & 18.22 & 18.36 & 0.14 & $0.42 / 0.16$ \\
\hline & 8.00 & 7.70 & 30.62 & 17.69 & 18.95 & 1.26 & $>4.00 / 0.16$ \\
\hline & 10.00 & 9.57 & 31.74 & 18.34 & 19.85 & 1.51 & $>4.00 / 0.17$ \\
\hline \multirow{5}{*}{$\mathrm{Fe}_{3} \mathrm{O}_{4}-\mathrm{GO}$} & 4.00 & 4.59 & 4.46 & 2.58 & 2.25 & -0.33 & $>4.00 / 0.12$ \\
\hline & 6.00 & 6.08 & 14.48 & 8.37 & 9.63 & 1.26 & $>4.00 / 0.09$ \\
\hline & 7.00 & 6.90 & 19.60 & 11.32 & 13.93 & 2.61 & $>4.00 / 0.10$ \\
\hline & 8.00 & 7.63 & 22.10 & 12.77 & 14.95 & 2.18 & $>4.00 / 0.14$ \\
\hline & 10.00 & 8.43 & 20.77 & 12.00 & 16.18 & 4.18 & $>4.00 / 0.11$ \\
\hline \multirow{5}{*}{$\mathrm{Fe}_{3} \mathrm{O}_{4}-\mathrm{AC}$} & 4.00 & 4.55 & 3.30 & 1.91 & 2.24 & 0.33 & $0.19 / 0.19$ \\
\hline & 6.00 & 6.06 & 9.95 & 5.75 & 6.17 & 0.43 & $0.16 / 0.16$ \\
\hline & 7.00 & 7.02 & 13.25 & 7.66 & 8.17 & 0.51 & $0.28 / 0.17$ \\
\hline & 8.00 & 7.62 & 17.11 & 9.89 & 9.06 & -0.83 & $0.34 / 0.11$ \\
\hline & 10.00 & 8.65 & 19.48 & 11.25 & 10.61 & -0.64 & $0.43 / 0.11$ \\
\hline
\end{tabular}

(1) Difference between actual TOC and theoretical TOC calculated from $\mathrm{H}_{2} \mathrm{BDC}$ concentration (TOC $\mathrm{H} 2 \mathrm{BDC}$ ). ${ }^{\text {(2) }} \mathrm{Fe}$ analyzed after separation with a magnet/after filtration.

A comparison between the concentration of $\mathrm{H}_{2} \mathrm{BDC}$ expressed as $\mathrm{mg} \mathrm{C} \mathrm{L}^{-1}$ ( $\mathrm{TOC}_{\mathrm{H} 2 \mathrm{BDC}}$ ) and the actual TOC values provides an insight into the leaching of carbon moieties from the materials. In general, Diff $\mathrm{TOC}$ was within the experimental error range of the analytical method (i.e., $\pm 0.5 \mathrm{mg} \mathrm{L}^{-1}$ ) suggesting that released carbon belonged mostly to $\mathrm{H}_{2} \mathrm{BDC}$. However, much larger Diff ${ }_{\mathrm{TOC}}$ values were observed for $\mathrm{Fe}_{3} \mathrm{O}_{4}-\mathrm{GO}$ at neutral and alkaline conditions. This can be related to the instability of GO in water and its reaction in alkaline media resulting in the release of humic-like structures to aqueous solution [28]. Iron was analyzed in aqueous solution as dissolved iron (sample filtered through $0.45 \mu \mathrm{m}$ PET membrane) and total iron (sample obtained by separation of the solid with a magnet). For samples from $\mathrm{Fe}_{3} \mathrm{O}_{4}$ runs, very low values of iron concentration were found, being no more than $0.2 \%$ of the maximum releasable amount according to the catalyst composition. The difference between total and dissolved iron was low, but still appreciable, especially at high $\mathrm{pH}$. This can be due to some instability of the material at alkaline conditions likely because of partial transformation of magnetite into goethite or maghemite in a dissolutionprecipitation process [51]. This effect was also observed for $\mathrm{Fe}_{3} \mathrm{O}_{4}-\mathrm{AC}$ to a similar extent. However, the difference between total and dissolved iron greatly increased in tests performed with graphene-based materials. In the case of $\mathrm{Fe}_{3} \mathrm{O}_{4}-\mathrm{G}$, at $\mathrm{pH} 8$ and 10, values of total Fe higher than $4 \mathrm{mg} \mathrm{L}^{-1}$ suggest the formation of iron oxide precipitates. Additionally, mechanical breakdown of the small particles (i.e., the graphene used as starting material had a particle size less than $2 \mu \mathrm{m}$ ) must be considered. Finally, in the case of $\mathrm{Fe}_{3} \mathrm{O}_{4}-\mathrm{GO}$, regardless of $\mathrm{pH}$, a higher amount of total iron as solid structures $\left(>4 \mathrm{mg} \mathrm{L}^{-1}\right)$ was detected compared with dissolved iron $\left(<0.15 \mathrm{mg} \mathrm{L}^{-1}\right)$. A combination of the above-mentioned effects together with the intrinsic instability of GO in water might be responsible of such iron leaching from the catalyst $[28,51]$. 
A key aspect in the performance of a catalyst is its stability under actual reaction conditions. The MBCs here prepared were intended for CWPO processes. Thus, the stability of the materials in the presence of $\mathrm{O}_{2}$ and $\mathrm{H}_{2} \mathrm{O}_{2}$ under simulated solar radiation was explored. For that, MBC samples were brought into contact with ultrapure water under agitation for $30 \mathrm{~min}$. Then, oxygen was bubbled, $\mathrm{H}_{2} \mathrm{O}_{2}$ was added (if necessary), and the aqueous suspension was irradiated for $3 \mathrm{~h}$. Table 6 shows the concentration of $\mathrm{H}_{2} \mathrm{BDC}$, TOC, and $\mathrm{pH}$ after some tests. Dissolved iron and total iron were always lower than $0.05 \mathrm{mg} \mathrm{L}^{-1}$ and $0.1 \mathrm{mg} \mathrm{L}^{-1}$, respectively. In this regard, it should be noticed that lower solid loadings were used $\left(0.2 \mathrm{~g} \mathrm{~L}^{-1}\right)$ compared with the previous long-term assays summarized in Table 5.

Table 6. Results from MBCs stability tests under oxidizing conditions.

\begin{tabular}{|c|c|c|c|c|c|}
\hline MBC & Test & $\begin{array}{l}\text { Time } \\
\text { (min) }\end{array}$ & $\begin{array}{c}\mathrm{H}_{2} \mathrm{BDC} \\
\left(\mathrm{mg} \mathrm{L}^{-1}\right)\end{array}$ & $\begin{array}{c}\text { TOC } \\
\left(\mathrm{mg} \mathrm{L}^{-1}\right)\end{array}$ & $\mathrm{pH}$ \\
\hline \multirow{4}{*}{$\mathrm{Fe}_{3} \mathrm{O}_{4}$} & \multirow{2}{*}{$\mathrm{Rad}+\mathrm{O}_{2}$} & 0 & 0.23 & 0.12 & 7.38 \\
\hline & & 180 & 0.29 & 0.52 & 7.35 \\
\hline & \multirow{2}{*}{$\mathrm{Rad}+\mathrm{O}_{2}+\mathrm{H}_{2} \mathrm{O}_{2}$} & 0 & 0.24 & 0.11 & 7.37 \\
\hline & & 180 & 0.00 & 0.55 & 7.30 \\
\hline \multirow{4}{*}{$\mathrm{Fe}_{3} \mathrm{O}_{4}-\mathrm{G}$} & \multirow{2}{*}{$\mathrm{Rad}+\mathrm{O}_{2}$} & 0 & 3.10 & 0.16 & 7.21 \\
\hline & & 180 & 3.18 & 1.27 & 6.10 \\
\hline & \multirow[t]{2}{*}{$\mathrm{Rad}+\mathrm{O}_{2}+\mathrm{H}_{2} \mathrm{O}_{2}$} & 0 & 3.14 & 0.17 & 7.20 \\
\hline & & 180 & 1.56 & 2.52 & 6.50 \\
\hline \multirow{4}{*}{$\mathrm{Fe}_{3} \mathrm{O}_{4}-\mathrm{GO}$} & \multirow{2}{*}{$\mathrm{Rad}+\mathrm{O}_{2}$} & 0 & 0.53 & 0.52 & 7.05 \\
\hline & & 180 & 1.02 & 1.23 & 6.35 \\
\hline & \multirow{2}{*}{$\mathrm{Rad}+\mathrm{O}_{2}+\mathrm{H}_{2} \mathrm{O}_{2}$} & 0 & 0.60 & 0.54 & 7.03 \\
\hline & & 180 & 0.00 & 2.05 & 5.92 \\
\hline \multirow{4}{*}{$\mathrm{Fe}_{3} \mathrm{O}_{4}-\mathrm{GO}$} & \multirow{2}{*}{$\mathrm{Rad}+\mathrm{O}_{2}$} & 0 & 0.76 & 0.10 & 7.63 \\
\hline & & 180 & 0.78 & 0.45 & 6.32 \\
\hline & \multirow{2}{*}{$\mathrm{Rad}+\mathrm{O}_{2}+\mathrm{H}_{2} \mathrm{O}_{2}$} & 0 & 1.27 & 0.11 & 7.65 \\
\hline & & 180 & 0.00 & 0.65 & 5.84 \\
\hline
\end{tabular}

In general, from Table 6 the desorption of some terephthalic acid from the materials during the initial 30 min dark stage (see $\mathrm{H}_{2} \mathrm{BDC}$ data at time 0 ) can be noticed. This effect was particularly evident for the $\mathrm{Fe}_{3} \mathrm{O}_{4}-\mathrm{G}$ sample. The amount of $\mathrm{H}_{2} \mathrm{BDC}$ in solution remained practically unchanged after the treatment with $\mathrm{Rad}+\mathrm{O}_{2}$ experiments but decreased significantly in $\mathrm{Rad}+\mathrm{O}_{2}+\mathrm{H}_{2} \mathrm{O}_{2}$ runs as a result of $\mathrm{H}_{2} \mathrm{BDC}$ oxidation by $\mathrm{HO}^{\bullet}$ generated in photo-Fenton reactions [52]. Contrarily, TOC increased especially in $\mathrm{Rad}+\mathrm{O}_{2}+\mathrm{H}_{2} \mathrm{O}_{2}$ runs because of breakdown of terephthalate molecule into smaller organic acids (see $\mathrm{pH}$ drops in Table 6) and $\mathrm{HO}^{\bullet}$ attack to carbon structures. In any case, $\mathrm{Fe}_{3} \mathrm{O}_{4}-\mathrm{AC}$ resulted in the highest stability among the three carbon MBCs synthesized in this work.

\subsection{Catalytic Activity of MBCs in CWPO Processes}

The catalytic activity of the as-prepared MBCs was studied for the degradation of MTP by heterogeneous Fenton and photo-Fenton processes. According to the accepted mechanism for these AOPs, the following reactions can be considered [7]:

$$
\begin{gathered}
\equiv \mathrm{Fe}^{2+}+\mathrm{H}_{2} \mathrm{O}_{2} \rightarrow \equiv \mathrm{Fe}^{3+}+\mathrm{OH}^{-}+\mathrm{HO}^{\bullet} \\
\equiv \mathrm{Fe}^{3+}+\mathrm{H}_{2} \mathrm{O}_{2} \rightarrow \equiv \mathrm{Fe}^{2+}+\mathrm{H}^{+}+\mathrm{HO}_{2}^{\bullet} \\
\mathrm{HO}_{2}^{\bullet}+\mathrm{OH}^{-} \rightarrow \mathrm{H}_{2} \mathrm{O}+\mathrm{O}_{2}^{\bullet-}
\end{gathered}
$$

where $\equiv \mathrm{Fe}^{3+}$ and $\equiv \mathrm{Fe}^{2+}$ represents the iron species on the catalyst surface. On the other hand, iron oxides can act as photocatalysts in the presence of UV-vis radiation:

$$
\equiv \mathrm{Fe}^{3+} / \equiv \mathrm{Fe}^{2+}+\mathrm{h} v \rightarrow \equiv \mathrm{Fe}^{3+} / \equiv \mathrm{Fe}^{2+}+\mathrm{h}^{+}+\mathrm{e}^{-}
$$




$$
\begin{gathered}
\mathrm{e}-+\mathrm{O}_{2} \rightarrow \mathrm{O}_{2}^{\bullet-} \\
2 \mathrm{O}_{2}^{\bullet-}+2 \mathrm{H}^{+} \rightarrow \mathrm{H}_{2} \mathrm{O}_{2}+\mathrm{O}_{2} \\
\mathrm{e}^{-}\left(\mathrm{O}_{2}^{\bullet-}\right)+\mathrm{H}_{2} \mathrm{O}_{2} \rightarrow \mathrm{OH}^{-}+\mathrm{HO}^{\bullet}\left(+\mathrm{O}_{2}\right)
\end{gathered}
$$

Moreover, radiation favors the regeneration of $\equiv \mathrm{Fe}^{2+}$ on the catalyst surface, increasing the generation of hydroxyl radicals:

$$
\equiv \mathrm{Fe}^{3+}+\mathrm{h} v+\mathrm{OH}^{-} \rightarrow \equiv \mathrm{Fe}^{2+}+\mathrm{HO}^{\bullet}
$$

The hydroxyl radicals generated through Reactions (4), (10), and (11) will be the main ones responsible for MTP degradation in aqueous media.

The evolution of MTP during dark CWPO and photo-CWPO using the four materials is depicted in Figure 8. It should be noticed that prior to oxidation runs, adsorption experiments in the dark were carried out to establish an adequate time for MTP adsorption equilibrium. This was nearly reached in $30 \mathrm{~min}$ using any of the four MBCs (not shown), with MTP removals of $17 \%$ for $\mathrm{Fe}_{3} \mathrm{O}_{4}-\mathrm{G}, 12 \%$ for $\mathrm{Fe}_{3} \mathrm{O}_{4}-\mathrm{AC}, 8 \%$ for $\mathrm{Fe}_{3} \mathrm{O}_{4}-\mathrm{GO}$, and less than $3 \%$ for $\mathrm{Fe}_{3} \mathrm{O}_{4}$. In addition, blank experiments of MTP with $\mathrm{H}_{2} \mathrm{O}_{2}$ both in the presence and absence of simulated solar radiation were carried out and negligible MTP removal was observed. As is apparent from Figure 8A, the catalytic activity of $\mathrm{Fe}_{3} \mathrm{O}_{4}$ in dark CWPO at room temperature (i.e., $20^{\circ} \mathrm{C}$ ) was rather low with only $5 \%$ of MTP conversion in $3 \mathrm{~h}$, likely due to a slow $\equiv \mathrm{Fe}^{3+} / \equiv \mathrm{Fe}^{2+}$ redox cycle (Reaction (5)) [53]. The presence of carbon structures in MBCs increased their adsorption capacity (see decrease in MTP concentration from -30 to $0 \mathrm{~min}$ in Figure 8) and the reaction rate of MTP removal to some extent (see data from 0 to $180 \mathrm{~min}$ in Figure 8A). However, the activity was still unsatisfactory for practical applications at the mild conditions of this work (i.e., ambient temperature and initial $\mathrm{pH} 7$ ) with less than $35 \%$ overall MTP removal and negligible mineralization (i.e., TOC removal) in $3 \mathrm{~h}$. In this sense, it is well-known that optimum $\mathrm{pH}$ for Fenton reactions is near 3 and that higher temperature (i.e., $50-90{ }^{\circ} \mathrm{C}$ ) would be also required to increase the efficiency of the catalytic activity of MBCs [6]. As expected from Reactions (7)-(11), simulated solar radiation greatly enhanced the process efficiency. Thus, MTP removals between $40 \%$ and $95 \%$ were observed depending on the MBC used (Figure $8 \mathrm{~B}$ ). In this case, the beneficial effect of carbon structures over bare $\mathrm{Fe}_{3} \mathrm{O}_{4}$ goes beyond the increase in the adsorption capacity of MTP. Table 7 shows the pseudo-first-order apparent rate constant of MTP removal for the four synthetized materials. As shown, the best results in terms of MTP removal rate were found for $\mathrm{Fe}_{3} \mathrm{O}_{4}-\mathrm{GO}$ and $\mathrm{Fe}_{3} \mathrm{O}_{4}-\mathrm{AC}$ composites.
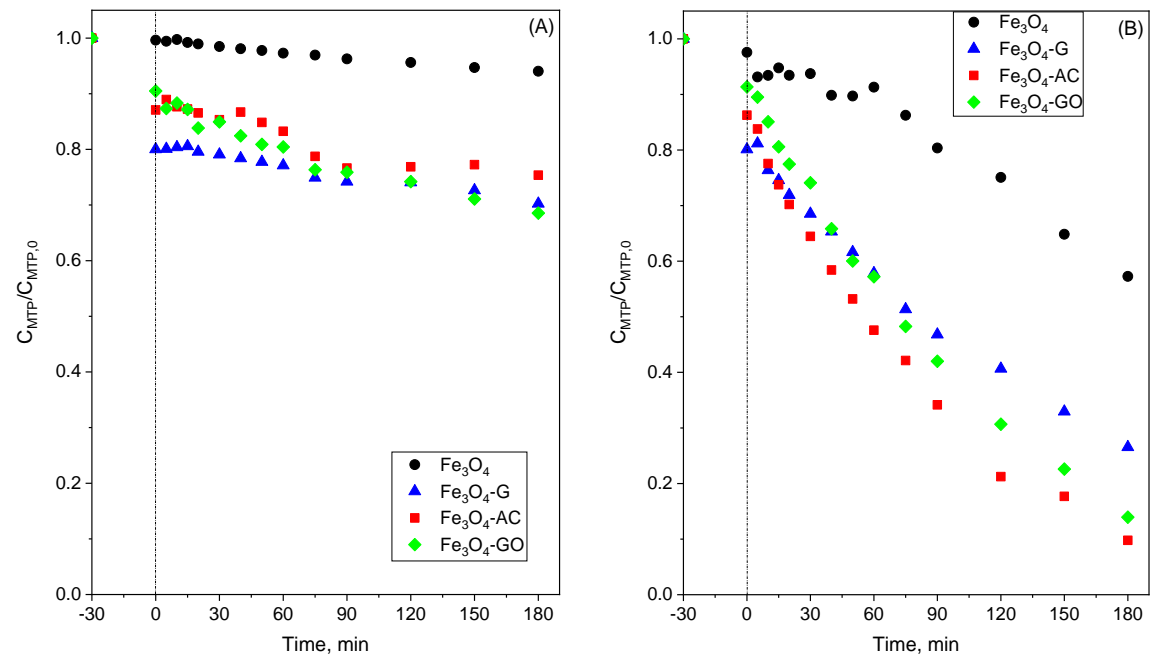

Figure 8. Evolution of MTP normalized concentration during (A) dark CWPO and (B) simulated solar radiation-assisted CWPO. Conditions: $\mathrm{C}_{\mathrm{MTP}, 0}=50 \mathrm{mg} \mathrm{L}^{-1}, \mathrm{C}_{\mathrm{MBC}}=0.2 \mathrm{~g} \mathrm{~L}^{-1}, \mathrm{pH}_{0}=7, \mathrm{~T}(\mathrm{~A})=20^{\circ} \mathrm{C}$, $\mathrm{T}(\mathrm{B})=40^{\circ} \mathrm{C}, \mathrm{C}_{\mathrm{H} 2 \mathrm{O} 2,0}=50 \mathrm{Mm}$, Irradiance $=581 \mathrm{Wm}^{-2}$. 
Table 7. Pseudo-first-order apparent kinetic constants for MTP degradation and efficiency of $\mathrm{H}_{2} \mathrm{O}_{2}$ utilization in photo-CWPO runs.

\begin{tabular}{|c|c|c|c|c|}
\hline Sample & Conditions & $\begin{array}{l}\mathbf{k}_{\text {app-MTP }} \\
\left(\min ^{-1}\right)\end{array}$ & $\mathbf{R}^{2}$ & $\begin{array}{c}\eta \text {-TOC- } \mathrm{H}_{2} \mathrm{O}_{2} \\
\left(\mathrm{~mol} \mathrm{C} / \mathrm{mol} \mathrm{H}_{2} \mathrm{O}_{2}\right)\end{array}$ \\
\hline $\mathrm{Fe}_{3} \mathrm{O}_{4}$ & $50 \mathrm{mM} \mathrm{H}_{2} \mathrm{O}_{2}, \mathrm{pH}_{0} 7$ & $2.5 \times 10^{-3}$ & 0.956 & 0.074 \\
\hline $\mathrm{Fe}_{3} \mathrm{O}_{4}-\mathrm{G}$ & $50 \mathrm{mM} \mathrm{H}_{2} \mathrm{O}_{2}, \mathrm{pH}_{0} 7$ & $6.0 \times 10^{-3}$ & 0.997 & 0.129 \\
\hline $\mathrm{Fe}_{3} \mathrm{O}_{4}-\mathrm{GO}$ & $50 \mathrm{mM} \mathrm{H}_{2} \mathrm{O}_{2}, \mathrm{pH}_{0} 7$ & $9.1 \times 10^{-3}$ & 0.998 & 0.079 \\
\hline $\mathrm{Fe}_{3} \mathrm{O}_{4}-\mathrm{AC}$ & $50 \mathrm{mM} \mathrm{H}_{2} \mathrm{O}_{2}, \mathrm{pH}_{0} 7$ & $9.6 \times 10^{-3}$ & 0.997 & 0.054 \\
\hline $\mathrm{Fe}_{3} \mathrm{O}_{4}-\mathrm{AC}$ & $50 \mathrm{mM} \mathrm{H}_{2} \mathrm{O}_{2}, \mathrm{pH} 7^{(*)}$ & $5.1 \times 10^{-3}$ & 0.996 & 0.026 \\
\hline $\mathrm{Fe}_{3} \mathrm{O}_{4}-\mathrm{AC}$ & $6.5 \mathrm{mM} \mathrm{H}_{2} \mathrm{O}_{2}, \mathrm{pH}_{0} 7$ & $1.7 \times 10^{-3}$ & 0.998 & 0.205 \\
\hline $\mathrm{Fe}_{3} \mathrm{O}_{4}-\mathrm{AC}$ & $10 \mathrm{mM} \mathrm{H}_{2} \mathrm{O}_{2}, \mathrm{pH}_{0} 7$ & $4.1 \times 10^{-3}$ & 0.991 & 0.230 \\
\hline $\mathrm{Fe}_{3} \mathrm{O}_{4}-\mathrm{AC}$ & $30 \mathrm{mM} \mathrm{H}_{2} \mathrm{O}_{2}, \mathrm{pH}_{0} 7$ & $7.4 \times 10^{-3}$ & 0.974 & 0.095 \\
\hline
\end{tabular}

(*) $\mathrm{pH}$ controlled during the run at 7.0.

TOC adsorbed onto the catalysts during the initial dark stage and overall TOC removal after the $180 \mathrm{~min}$ photo-treatment are presented in Figure 9. It is apparent that overall TOC removal achieved in the process catalyzed by $\mathrm{Fe}_{3} \mathrm{O}_{4}$ was rather low though significantly increased using the carbon composites. Thus, the highest TOC removal (21\%) was obtained with the $\mathrm{Fe}_{3} \mathrm{O}_{4}$-AC catalyst.

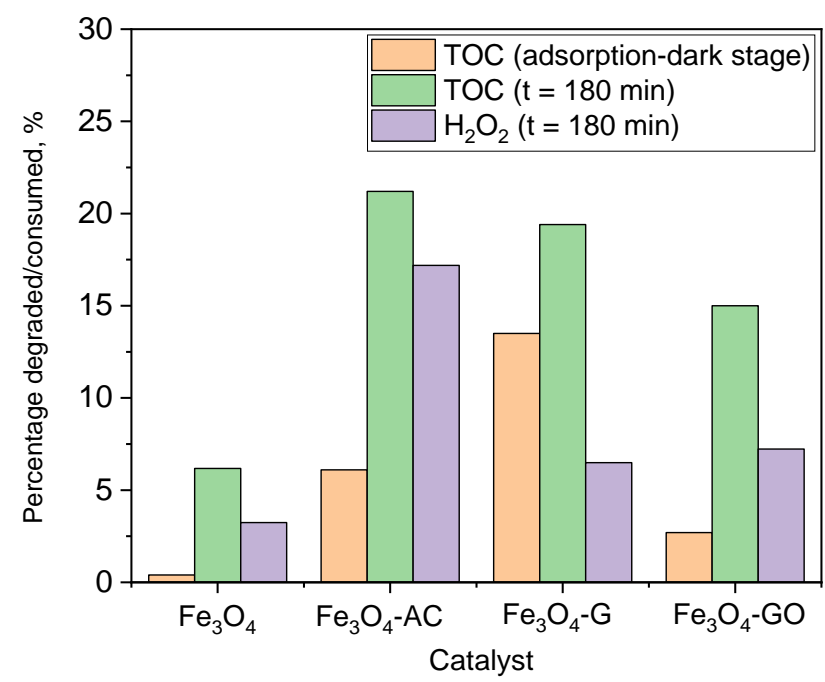

Figure 9. Percentages of TOC removal and $\mathrm{H}_{2} \mathrm{O}_{2}$ depletion during photo-CWPO of MTP. Conditions: $\mathrm{C}_{\mathrm{MTP}, 0}=50 \mathrm{mg} \mathrm{L}^{-1}, \mathrm{C}_{\mathrm{MBC}}=0.2 \mathrm{~g} \mathrm{~L}^{-1}, \mathrm{pH}_{0}=7, \mathrm{~T}=40^{\circ} \mathrm{C}, \mathrm{C}_{\mathrm{H} 2 \mathrm{O} 2,0}=50 \mathrm{mM}$, Irradiance $=581 \mathrm{~W} \mathrm{~m}^{-2}$.

An efficient use of $\mathrm{H}_{2} \mathrm{O}_{2}$ is a key aspect in the performance of CWPO processes. In this work, the efficient use of $\mathrm{H}_{2} \mathrm{O}_{2}$ was examined by a mineralization efficiency factor defined as TOC removed (mol C) per mol of $\mathrm{H}_{2} \mathrm{O}_{2}$ consumed, $\eta-\mathrm{TOC}-\mathrm{H}_{2} \mathrm{O}_{2}$. According to the stoichiometry of the theoretical reaction between MTP and $\mathrm{H}_{2} \mathrm{O}_{2}$ to yield $\mathrm{CO}_{2}$ and $\mathrm{H}_{2} \mathrm{O}$ (i.e., mineralization), a $\eta-\mathrm{TOC}-\mathrm{H}_{2} \mathrm{O}_{2}$ value of $0.38 \mathrm{~mol} \mathrm{C} / \mathrm{mol} \mathrm{H}_{2} \mathrm{O}_{2}$ was calculated. This represents the maximum attainable efficiency factor. As can be seen in Table 7 , actual $\eta$-TOC$\mathrm{H}_{2} \mathrm{O}_{2}$ values were well below this maximum because of inefficient $\mathrm{H}_{2} \mathrm{O}_{2}$ decomposition and $\mathrm{HO}^{\bullet}$ reactions (e.g., $\mathrm{H}_{2} \mathrm{O}_{2}$ auto-scavenging effect, termination steps of the free radical reaction mechanism, and $\mathrm{HO}^{\bullet}$ reactions with carbon materials). Comparing the different MBCs, the highest efficiency was achieved with $\mathrm{Fe}_{3} \mathrm{O}_{4}-\mathrm{G}$, likely due to its higher surface area and MTP adsorption capacity. Moreover, higher inefficient consumption of $\mathrm{H}_{2} \mathrm{O}_{2}$ was expected for $\mathrm{Fe}_{3} \mathrm{O}_{4}$-AC according to previous studies [54].

As discussed before, the degradation of MTP takes place mainly through the attack of hydroxyl radicals formed from $\mathrm{H}_{2} \mathrm{O}_{2}$ decomposition. Several steps are expected until complete MTP mineralization, which involve the formation of different intermediate compounds. The final degradation step intermediates are usually short-chain organic acids like 
oxalic, acetic, and formic acids [55,56]. As shown in Table 8, noticeable concentrations of these acids were found after $3 \mathrm{~h}$ of treatment, being formic acid predominant. It should be pointed out that oxalic acid might be fast degraded during iron-photocatalytic treatments through the ligand-charge-metal transition mechanism, which also favor mineralization and reduce the iron leaching $[57,58]$. Total iron and terephthalic acid released into the reaction medium were also analyzed and presented in Table 8. As observed, the concentration of total iron was lower than $0.12 \mathrm{mg} \mathrm{L}^{-1}$ regardless of the material used. At such low concentrations, contribution of homogeneous photo-Fenton reactions to MTP degradation was negligible. The amount of $\mathrm{H}_{2} \mathrm{BDC}$ remaining in solution after CWPO runs was also small, the highest value found in the $\mathrm{Fe}_{3} \mathrm{O}_{4}-\mathrm{G}$ run being in agreement with results discussed in Section 2.3.

Table 8. Concentrations of short-chain organic acids, iron, and terephthalic acid after photo-CWPO runs.

\begin{tabular}{|c|c|c|c|c|c|}
\hline MBC & $\begin{array}{c}\mathrm{C}_{\text {Acetic Acid }} \\
\left(\mathrm{mg} \mathrm{L}^{-1}\right)\end{array}$ & $\begin{array}{c}\text { C Formic Acid }_{\text {Fid }} \\
\left(\mathrm{mg} \mathrm{L}^{-1}\right)\end{array}$ & $\begin{array}{c}\text { Coxalic Acid }_{\text {Ocid }} \\
\left(\mathrm{mg} \mathrm{L}^{-1}\right)\end{array}$ & $\begin{array}{c}\mathrm{Fe} \\
\left(\mathrm{mg} \mathrm{L}^{-1}\right)\end{array}$ & $\begin{array}{c}\mathrm{C}_{\text {H2BDC }} \\
\left(\mathrm{mg} \mathrm{L}^{-1}\right)\end{array}$ \\
\hline $\mathrm{Fe}_{3} \mathrm{O}_{4}$ & 0.44 & 2.85 & 0.86 & 0.12 & 0.23 \\
\hline $\mathrm{Fe}_{3} \mathrm{O}_{4}-\mathrm{G}$ & 2.42 & 12.5 & 2.16 & 0.06 & 3.40 \\
\hline $\mathrm{Fe}_{3} \mathrm{O}_{4}-\mathrm{GO}$ & 2.10 & 10.2 & 2.33 & 0.07 & 1.06 \\
\hline $\mathrm{Fe}_{3} \mathrm{O}_{4}-\mathrm{AC}$ & 1.97 & 13.4 & 3.65 & 0.06 & 0.88 \\
\hline
\end{tabular}

\subsection{Improved Use of $\mathrm{Fe}_{3} \mathrm{O}_{4}$-AC Catalyst}

In view of the above results, $\mathrm{Fe}_{3} \mathrm{O}_{4}-\mathrm{AC}$ was the most promising catalyst among the MBCs here studied due to higher MTP and TOC conversions and greater stability in CWPO as well as lower cost of the carbonaceous material (laboratory prices from the suppliers indicate that $\mathrm{G}$ and $\mathrm{GO}$ are about 4 and 300 times more expensive than $\mathrm{AC}$, respectively). Nevertheless, improvement of the catalyst synthesis and the optimization of CWPO treatment conditions (e.g., $\mathrm{pH}$, temperature, $\mathrm{H}_{2} \mathrm{O}_{2}$ dosage, treatment time, etc.) might eventually lead to a substantial enhancement of the catalyst performance. In line with this, the impact of further purification of the $\mathrm{Fe}_{3} \mathrm{O}_{4}-\mathrm{AC}$ catalyst, its performance in $\mathrm{CWPO}$ treatment at circumneutral $\mathrm{pH}$, and the effect of $\mathrm{H}_{2} \mathrm{O}_{2}$ dose were examined.

One of the key aspects of this work is the development of a green synthesis of MBCs with full recovery of the terephthalic acid use a mediator in the procedure. Although relatively low amounts of $\mathrm{H}_{2} \mathrm{BDC}$ remained on the catalyst after the synthesis, a further washing step with $\mathrm{NaOH}$ solution $(\mathrm{pH}=10)$ and rinsing water to remove retained $\mathrm{H}_{2} \mathrm{BDC}$ to a higher extent proved useful. In Figure 10, MTP removal rate and $\mathrm{pH}$ evolution during CWPO experiments using the material without the additional alkaline washing step $\left(\mathrm{Fe}_{3} \mathrm{O}_{4}-\mathrm{AC}\right)$ and after treatment with aqueous $\mathrm{NaOH}\left(\mathrm{Fe}_{3} \mathrm{O}_{4}\right.$ - $\mathrm{AC}$-alkaline washed) are presented. Similar evolution of MTP and a slightly smaller drop in the initial $\mathrm{pH}$ during CWPO demonstrated that the process efficiency was not greatly affected by the additional washing step but no accumulation of $\mathrm{H}_{2} \mathrm{BDC}$ during the experiment with the $\mathrm{Fe}_{3} \mathrm{O}_{4}$-AC-alkaline catalyst was observed.

To assess the catalytic process performance of $\mathrm{Fe}_{3} \mathrm{O}_{4}-\mathrm{AC}$ in the CWPO of MTP at circumneutral $\mathrm{pH}$, an experiment was completed controlling the $\mathrm{pH}$ at 7 throughout the run. Figure 10 shows that MTP removal rate was somewhat slower than in the corresponding $\mathrm{pH}$-free experiment (notice decrease of $\mathrm{pH}$ up to 3.5-4) but still higher than that observed with bare $\mathrm{Fe}_{3} \mathrm{O}_{4}$. This is a promising result with this material because one of the main drawbacks of CWPO technologies is a relatively low efficiency at circumneutral $\mathrm{pH}$ [59]. 



Figure 10. Evolution of MTP (A) and $\mathrm{pH}(\mathbf{B})$ during photo-CWPO processes with $\mathrm{Fe}_{3} \mathrm{O}_{4}$ and $\mathrm{Fe}_{3} \mathrm{O}_{4}$-AC materials. Conditions: $\mathrm{C}_{\mathrm{MTP}, 0}=50 \mathrm{mg} \mathrm{L}^{-1}, \mathrm{C}_{\mathrm{MBC}}=0.2 \mathrm{~g} \mathrm{~L}^{-1}, \mathrm{pH}_{0}=7, \mathrm{~T}=40^{\circ} \mathrm{C}$, $\mathrm{C}_{\mathrm{H} 2 \mathrm{O} 2,0}=50 \mathrm{mM}$, Irradiance $=581 \mathrm{~W} \mathrm{~m}^{-2}$.

Another important fact found when carbonaceous materials are used as catalysts or supports in CWPO is the inefficient consumption of $\mathrm{H}_{2} \mathrm{O}_{2}$ under certain conditions [60,61]. In this sense, the dosage of $\mathrm{H}_{2} \mathrm{O}_{2}$ applied plays a crucial role. Theoretically, the optimum $\mathrm{H}_{2} \mathrm{O}_{2}$ dose (stoichiometric dose) to be applied for mineralization of MTP (i.e., complete conversion to $\mathrm{CO}_{2}, \mathrm{H}_{2} \mathrm{O}$ and $\mathrm{NO}_{3}{ }^{-}$) is $89 \mathrm{~mol} \mathrm{H}_{2} \mathrm{O}_{2} / \mathrm{mol} \mathrm{MTP} \mathrm{(as} \mathrm{metoprolol} \mathrm{tartrate).} \mathrm{Since}$ the experiments carried out in this work were completed with an MTP initial concentration of $50 \mathrm{mg} \mathrm{L}^{-1}$ (i.e., $0.073 \mathrm{mM}$ ), the theoretical initial concentration of $\mathrm{H}_{2} \mathrm{O}_{2}$ to mineralize MTP was calculated as $6.5 \mathrm{mM}$. Photo-CWPO experiments with initial $\mathrm{H}_{2} \mathrm{O}_{2}$ concentration in the $6.5-50 \mathrm{mM}$ range were performed, and the obtained results are presented in Figure 11 and Table 7. Although the rate of MTP removal was clearly influenced by the $\mathrm{H}_{2} \mathrm{O}_{2}$ dose (the higher the $\mathrm{H}_{2} \mathrm{O}_{2}$ concentration the higher the apparent rate constant $\mathrm{k}_{\text {app-MTP) minor }}$ differences were observed in TOC removal. As a consequence, the mineralization efficiency reached a maximum value $\left(\eta-T O C-\mathrm{H}_{2} \mathrm{O}_{2}=0.23 \mathrm{~mol} \mathrm{C} / \mathrm{mol} \mathrm{H}_{2} \mathrm{O}_{2}\right.$ ) for an initial concentration of $\mathrm{H}_{2} \mathrm{O}_{2} 10 \mathrm{mM}$ (Figure 11B). Still, this efficiency value is far from the theoretical $0.38 \mathrm{~mol} \mathrm{C} / \mathrm{mol} \mathrm{H}_{2} \mathrm{O}_{2}$ due to the refractory nature of some MTP degradation intermediates and the auto-scavenging effect of $\mathrm{H}_{2} \mathrm{O}_{2}$, which also reacts with $\mathrm{HO}^{\bullet}$ and other reactive oxygen species [62].
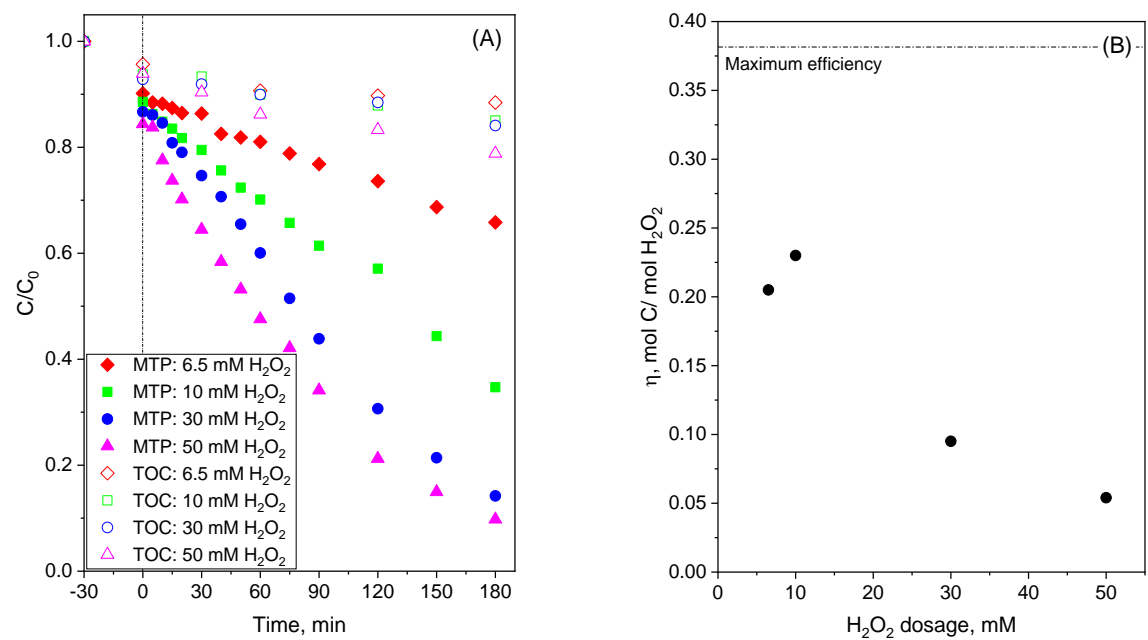

Figure 11. (A) MTP and TOC removals and (B) efficiency of $\mathrm{H}_{2} \mathrm{O}_{2}$ use in MTP mineralization. Effect of $\mathrm{H}_{2} \mathrm{O}_{2}$ dosage. Conditions: $\mathrm{C}_{\mathrm{MTP}, 0}=50 \mathrm{mg} \mathrm{L}-1, \mathrm{C}_{\mathrm{MBC}}=0.2 \mathrm{~g} \mathrm{~L}^{-1}, \mathrm{pH}_{0}=7, \mathrm{~T}=40^{\circ} \mathrm{C}$, Irradiance $=581 \mathrm{~W} \mathrm{~m}^{-2}$. 


\subsection{Reuse of $\mathrm{Fe}_{3} \mathrm{O}_{4}-\mathrm{AC}$ Catalyst}

One of the main challenges in developing a catalyst is to ensure good long-term performance. To study the reusability of the $\mathrm{Fe}_{3} \mathrm{O}_{4}-\mathrm{AC}$ catalyst, nine consecutive CWPO runs were carried out. The catalyst was recovered with an external magnet after each run and used in the next one without further treatment. Total iron and $\mathrm{H}_{2} \mathrm{BDC}$ concentrations at the end of each cycle were always lower than $0.15 \mathrm{mg} \mathrm{L}^{-1}$ and $0.5 \mathrm{mg} \mathrm{L}^{-1}$, which proved good catalyst stability. Figure 12 shows overall MTP and TOC removals by solar assisted CWPO. Additionally, the percentage of MTP adsorbed onto the catalysts after the initial dark stage is presented. It can be seen that overall removal of MTP dropped from 90 to ca. $75 \%$ after nine cycles, with a similar trend for TOC (from $21 \%$ to $10 \%$ ). This loss of catalytic performance took place within the first four cycles mainly. It can be related to the loss of the adsorption capacity of the catalyst for MTP, which decreased from $12 \%$ (first cycle) to c.a. $6 \%$ (from second to ninth cycles). The analysis of the $\mathrm{N}_{2}$ adsorption-desorption isotherm of a catalyst sample after the fifth cycle, when the main drop in catalytic activity had already been observed, confirmed a decrease in BET surface area and especially in micropore volume (see Table 4), which are mainly responsible for the adsorption phenomena in activated carbons. This effect is usually related to the presence of organic matter occupying micropores, although may also be due to the collapse of micropores walls due to the oxidation environment of CWPO. In this line, the elemental analysis of the reused catalyst showed an increase in the contents of carbon (from $32 \%$ to $40 \%$ ), nitrogen (from $0.2 \%$ to $0.4 \%$ ), and hydrogen (from $0.7 \%$ to $1.2 \%$ ). Besides, although the presence of adsorbed organic matter in carbonaceous materials is difficult to confirm by FTIR due to the overlapping of various bands, in Figure 5, two visible bands in the reused sample, located at $1160 \mathrm{~cm}^{-1}$ and $1725 \mathrm{~cm}^{-1}$, suggest the presence of phenolic and carboxyl moieties adsorbed onto the carbon surface [63]. These results points to the presence of organic compounds (i.e., MTP and degradation products) adsorbed onto the catalyst surface.

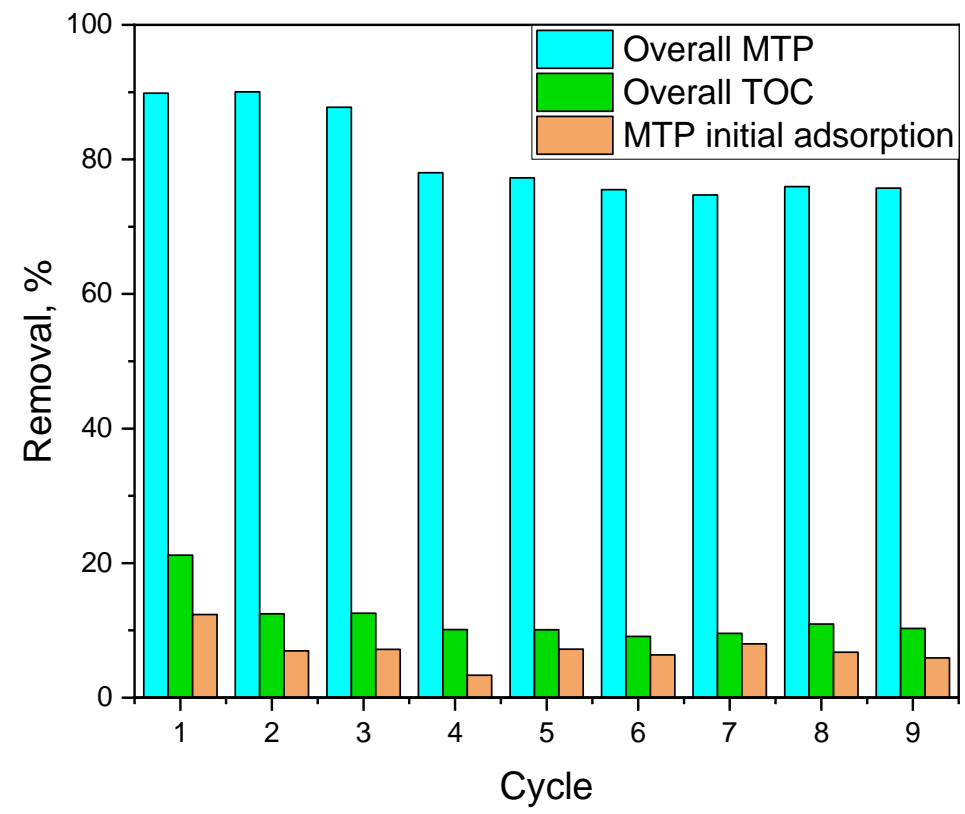

Figure 12. Percentage removals of MTP and TOC during CWPO runs reusing the $\mathrm{Fe}_{3} \mathrm{O}_{4}$-AC catalyst. Conditions: $\mathrm{C}_{\mathrm{MTP}, 0}=50 \mathrm{mg} \mathrm{L}^{-1}, \mathrm{C}_{\mathrm{MBC}}=0.2 \mathrm{~g} \mathrm{~L}^{-1}, \mathrm{pH}_{0}=7, \mathrm{~T}=40^{\circ} \mathrm{C}$, Irradiance $=581 \mathrm{~W} \mathrm{~m}^{-2}$.

On the other hand, at the oxidizing conditions applied in CWPO, some $\equiv \mathrm{Fe}^{2+}$ active sites might be oxidized to $\equiv \mathrm{Fe}^{3+}$, thus lowering the catalytic activity and the saturation magnetization to some extent. Accordingly, the saturation magnetization decreased from 38.7 to $32.9 \mathrm{emu} \mathrm{g}^{-1}$ after the repetitive use of the catalyst, which might be related to the 
partial transformation of surface magnetite into maghemite. The oxidation state of iron was studied by means of X-ray photoelectron spectroscopy (XPS). The high-resolution spectra of Fe $2 \mathrm{p}$ spectral region is presented in Figure 13 for fresh and reused catalysts. The peak positions of $\mathrm{Fe} 2 \mathrm{p}_{3 / 2}$ and $\mathrm{Fe} 2 \mathrm{p}_{1 / 2}$ and the satellite signals are consistent with the existence of magnetite and other $\equiv \mathrm{Fe}^{3+}$ species in both samples. The spectra were curve-fitted to a combination of Gaussian-Lorentzian functions using a Shirley-type background for peak analysis according to Grosvenor et al. [64]. The ratio between the areas of the $\mathrm{Fe}^{3+}$ and $\mathrm{Fe}^{2+}$ peaks in the $\mathrm{Fe} 2 \mathrm{p}_{3 / 2}$ zone slightly changed from 4.78 (fresh $\mathrm{Fe}_{3} \mathrm{O}_{4}$-AC) to 4.97 (reused $\mathrm{Fe}_{3} \mathrm{O}_{4}$-AC in nine consecutive CWPO runs), which confirmed that the oxidation takes place to a low extent. Despite these structural changes in the catalyst, its catalytic activity was maintained from the fourth run onwards and was still easily separable with a magnet.

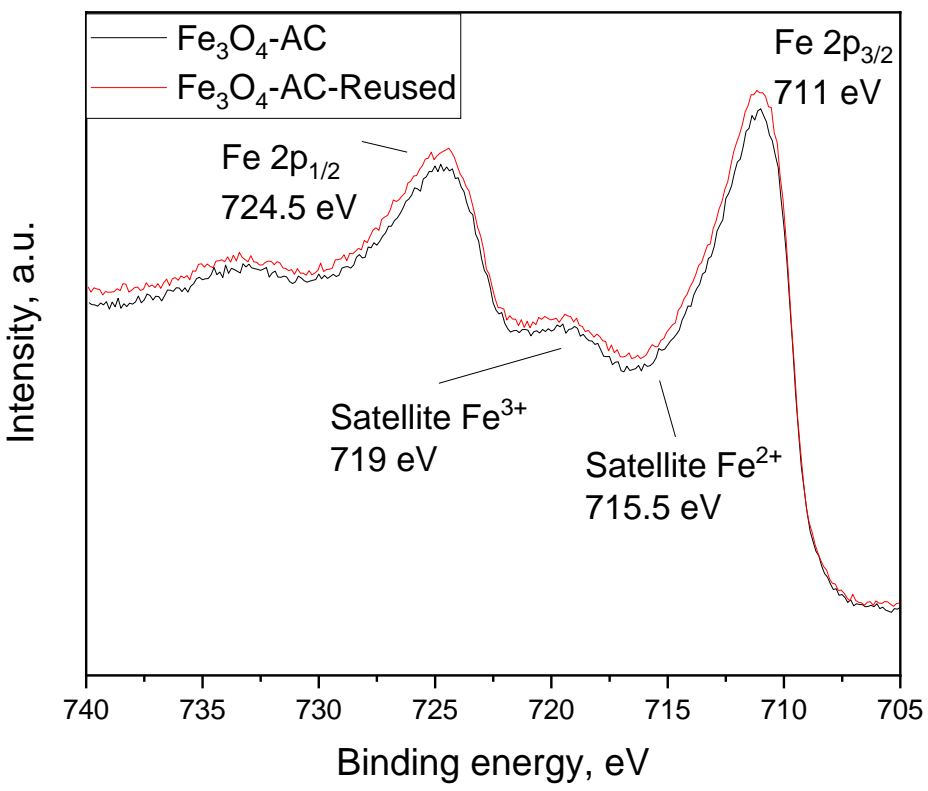

Figure 13. High-resolution XPS spectra of $\mathrm{Fe} 2 \mathrm{p}$ region of fresh and reused $\mathrm{Fe}_{3} \mathrm{O}_{4}-\mathrm{AC}$ catalyst after CWPO.

\section{Materials and Methods}

\subsection{Materials}

Terephthalic acid (1,4-benzenedicarboxylic acid, $\mathrm{C}_{6} \mathrm{H}_{4}(\mathrm{COOH})_{2}$, purity $\geq 98 \%, \mathrm{H}_{2} \mathrm{BDC}$ in this work), iron (II) chloride tetrahydrate $\left(\mathrm{FeCl}_{2} \cdot 4 \mathrm{H}_{2} \mathrm{O}\right.$; purity $\left.\geq 98 \%\right)$, metoprolol tartrate $\left(\left(\mathrm{C}_{15} \mathrm{H}_{25} \mathrm{NO}_{3}\right)_{2} \cdot \mathrm{C}_{4} \mathrm{H}_{6} \mathrm{O}_{6}\right.$, MTP, purity $\left.\geq 99 \%\right)$, sodium hydroxide $(\mathrm{NaOH}$, purity $\geq 98 \%$ purity), hydrochloric acid ( $\mathrm{HCl}, 37$ wt.\% ), hydrogen peroxide $\left(\mathrm{H}_{2} \mathrm{O}_{2}, 30 \mathrm{wt} \%\right.$ ), and phosphoric acid $\left(\mathrm{H}_{3} \mathrm{PO}_{4}, 85.5 \mathrm{wt}\right.$.\%) were used as received from commercial suppliers (Sigma-Aldrich and Panreac, Bogotá, Colombia) without any further purification. Ultrapure water (UP) was produced by a Milli-Q academic system (Millipore, Burlington, MA, USA). Commercial Darco 12-20 granular activated carbon (AC) from Sigma-Aldrich was milled to obtain particle size $<125 \mu \mathrm{m}$ prior use (specific surface area $650 \mathrm{~m}^{2} \mathrm{~g}^{-1}$ ); commercial xGnP graphene nanoplatelets (GP) from Sigma-Aldrich were used as received (particle size $<2 \mu \mathrm{m}$, thickness few nm, specific surface area $750 \mathrm{~m}^{2} \mathrm{~g}^{-1}$ ); and graphene oxide powder (GO) from Graphenea (particle size $<25-28 \mu \mathrm{m}$, specific surface area $>100 \mathrm{~m}^{2} \mathrm{~g}^{-1}$ ) were used for catalyst synthesis.

\subsection{Synthesis of $M B C s$}

Magnetite and composite catalysts were prepared by the novel procedure described in the Spanish Patent Application P202030544, based in green synthesis philosophy with non-toxic reagents, low energy consumption, and reagents recovery. Four materials were synthesized: bare magnetite $\left(\mathrm{Fe}_{3} \mathrm{O}_{4}\right)$ and three carbon magnetic composites $\left(\mathrm{Fe}_{3} \mathrm{O}_{4}-\mathrm{AC}\right.$, 
$\mathrm{Fe}_{3} \mathrm{O}_{4}-\mathrm{G}$, and $\mathrm{Fe}_{3} \mathrm{O}_{4}-\mathrm{GO}$ ). Following the procedure depicted in Figure $13,1 \mathrm{~g}$ of $\mathrm{FeCl}_{2} \cdot{ }_{4} \mathrm{H}_{2} \mathrm{O}$ was dissolved in $50 \mathrm{~mL}$ of deionized water (solution $\mathrm{A}$ ). Then, if required, $0.3 \mathrm{~g}$ of AC, GP or GO were added and dispersed into solution A by means of 15 min ultrasonication at ambient temperature. For the synthesis of bare magnetite (i.e., $\mathrm{Fe}_{3} \mathrm{O}_{4}$ sample), no solid was dispersed into solution $\mathrm{A}$. On the other hand, $0.835 \mathrm{~g}$ of $\mathrm{H}_{2} \mathrm{BDC}$ were dissolved in $20 \mathrm{~mL}$ of aqueous $\mathrm{NaOH} 1 \mathrm{M}$ (solution B). Subsequently, solution A was mechanically stirred at $800 \mathrm{rpm}$ and solution $\mathrm{B}$ was added dropwise during $1 \mathrm{~min}$. The mixture was kept at ambient temperature and $800 \mathrm{rpm}$ for $24 \mathrm{~h}$ to allow for the formation of the MBC. After that, the solid was separated by means of a neodymium external magnet and then repeatedly washed with $200 \mathrm{~mL}$ of deionized water to ensure a solid free of precursors. Iron and terephthalic acid were measured in the washing waters until negligible values were obtained. The solid was finally dried overnight at $60^{\circ} \mathrm{C}$, milled, and kept in a desiccator until use. The alkaline solution obtained after the magnetic separation of the catalyst contained terephthalate, $\mathrm{Na}^{+}$, and $\mathrm{Cl}^{-}$with traces (ppm level) of non-reacted $\mathrm{Fe}^{2+}$ or $\mathrm{Fe}^{3+}$ ions. Addition of concentrated $\mathrm{HCl}$ solution $(37 \mathrm{wt} . \%$ ) to $\mathrm{pH}<3$ led to the precipitation of $\mathrm{H}_{2} \mathrm{BDC}$ (solubility $0.0015 \mathrm{~g} / 100 \mathrm{~mL}$ at $20^{\circ} \mathrm{C}$ and $\mathrm{pH}=3$ ). This solid was recovered by filtration and reused as shown in Figure 14. A sample of recovered $\mathrm{H}_{2} \mathrm{BDC}$ was dried at $100{ }^{\circ} \mathrm{C}$ for $24 \mathrm{~h}$ and characterized to determine its composition.

Make-up $\mathrm{H}_{2} \mathrm{BDC} \quad$ Recovered $\mathrm{H}_{2} \mathrm{BDC}$ (>95\% recovery)

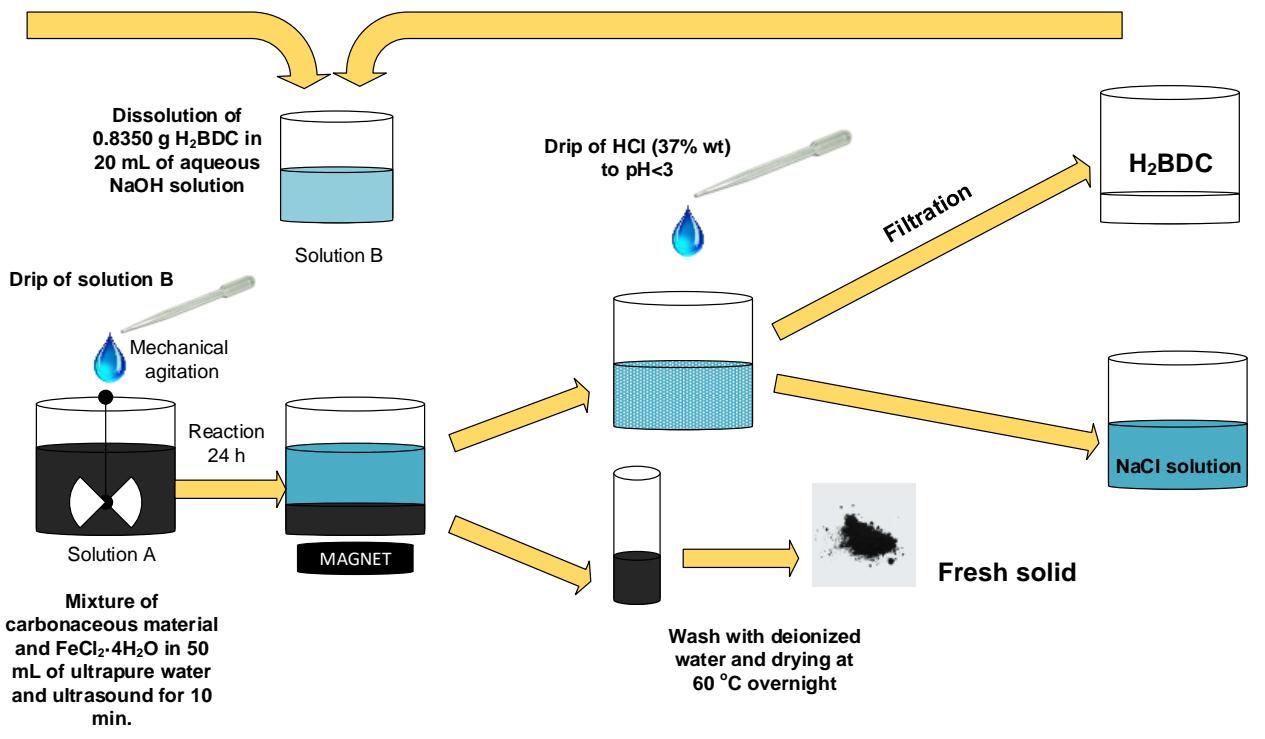

Figure 14. Green synthesis of MBCs.

\subsection{Characterization of Catalysts}

The study of the crystalline phase of solids by X-ray diffraction (XRD) was carried out on a powder Bruker D8 Advance XRD diffractometer with a $\mathrm{Cu} \mathrm{K} \alpha 1$ radiation $(\lambda=1.541$ Á ) coupled to a linear detector VANTEC (aperture $3^{\circ}$ ). The data sets were collected in the range of $2 \theta=5-70^{\circ}$ with a step size of $0.01^{\circ}$ and $0.5 \mathrm{~s}$ of sampling per point. Thermogravimetric and differential thermal analyses (TGA-DTA) were carried out with a thermobalance STA 449 F3 Jupiter-Netzsch coupled to a mass spectrometer QMS 403D Aëolos III-Netzsch SETSYS Evolution-16 (SETARAM, Lyon, France) apparatus using $100 \mathrm{~mL} \mathrm{~min}{ }^{-1}$ of argon and oxygen $(80 / 20, v / v)$ at a heating rate of $10^{\circ} \mathrm{C} \mathrm{min}-1$, from $40^{\circ} \mathrm{C}$ to $950{ }^{\circ} \mathrm{C}$. Nitrogen adsorption-desorption isotherms were used to study the BET surface area and pore volume of the materials. The equipment used to acquire them at $-196{ }^{\circ} \mathrm{C}$ was an Autosorb iQ2-C Series (Quantachrome, Boynton Beach, FL, USA) apparatus. Before analysis, the samples were degassed at $150{ }^{\circ} \mathrm{C}$ for $10 \mathrm{~h}$ under a residual pressure $<10^{-2}$ mbar. The t-plot method was applied to determine the volume of micropores. The mass percentages of nitrogen, hydrogen, and carbon solid samples were determined with a C-H-N-S TRUSPEC 
MICRO elemental analyzer (LECO). Wavelength dispersive X-ray fluorescence spectroscopy (WDXRF) was performed using a S8 Tiger (Bruker, Karlsruhe, Germany) apparatus to quantify the amount of iron in the samples. Magnetic measurements were performed using a Quantum Design MPMS XL-7 Superconducting Quantum Interference Device (SQUID). Fourier-transformed infrared spectroscopy (FTIR) was carried out using the $\mathrm{KBr}$ pellet method on a Nicolet iS10 spectrometer. Sampling resolution was set at $1 \mathrm{~cm}^{-1}$ and 32 scans from 400 to $4000 \mathrm{~cm}^{-1}$ wavenumber range. Surface chemical composition was studied by X-ray photoelectron spectroscopy (XPS) on a PHI VersaProbe II Scanning XPS Microprobe spectrometer equipped with scanning monochromatic X-ray $\mathrm{Al} \mathrm{K} \alpha$ radiation (200 $\mu \mathrm{m}$ area analyzed, $52.8 \mathrm{~W}$ and $15 \mathrm{kV}$ and $\mathrm{h} v=1486.6 \mathrm{eV}$ ) as the excitation source and a multi-channel hemispherical electron analyzer (pass energy of $29.35 \mathrm{eV}$ ). Binding energies were calibrated to the $C 1 \mathrm{~s}$ peak from the carbon signal at $284.8 \mathrm{eV}$. Raman spectra were acquired using an excitation laser source $(\lambda=630 \mathrm{~nm})$ on a Thermo Scientific Nicolet Almega XR dispersive Raman spectrometer.

\subsection{Stability Tests}

The stability of MBCs in water was tested at different $\mathrm{pH}(4,6,7,8$, and 10$)$ in a $0.01-\mathrm{M}$ phosphate-buffered solution. The experiments were carried out in a thermostatic orbital shaker at $25^{\circ} \mathrm{C}$. MBC samples $\left(1 \mathrm{~g} \mathrm{~L}^{-1}\right)$ were suspended into $20 \mathrm{~mL}$ of buffered solution and kept in $50 \mathrm{~mL}$ stoppered glass bottles under stirring for 7 days. After that, the solid was separated by an external magnet and the liquid phase analyzed to determine dissolved and total iron, $\mathrm{H}_{2} \mathrm{BDC}, \mathrm{TOC}$, and $\mathrm{pH}$. Additionally, catalyst stability was also studied at oxidizing conditions. Typically, MBC samples $\left(0.2 \mathrm{~g} \mathrm{~L}^{-1}\right)$ were suspended into $250 \mathrm{~mL}$ of ultrapure water in a $300 \mathrm{~mL}$ borosilicate glass vessel and allowed for homogenization for $30 \mathrm{~min}$. Then, if required, $\mathrm{H}_{2} \mathrm{O}_{2}$ was added to achieve $50 \mathrm{mM}$ concentration. The vessel was placed in the chamber of a solar box (Suntest CPS+, Atlas Material Testing Technology LLC, Madrid, Spain) equipped with a $1500 \mathrm{~W}$ air-cooled Xe lamp. The overall irradiance $(\lambda=300-800 \mathrm{~nm})$ at the photoreactor level was measured with an UV-Vis spectroradiometer (Black Comet C, StellarNet Inc., Tampa, FL, USA), resulting in $581.4 \mathrm{~W} \mathrm{~m}^{-2}$. The temperature of the simulator chamber was controlled at $40^{\circ} \mathrm{C}$. The experimental set-up has been described in previous works [52,65]. The vessel content was irradiated for $3 \mathrm{~h}$ under oxygen bubbling $\left(10 \mathrm{~L} \mathrm{~h}^{-1}\right)$. After that time, the solid was magnetically separated and dissolved and total iron, $\mathrm{H}_{2} \mathrm{BDC}, \mathrm{TOC}$, and $\mathrm{pH}$ were analyzed in liquid samples.

\subsection{Catalytic Activity Tests}

CWPO activity tests of magnetic solids in water were performed in a 300-mL borosilicate glass vessel provided with magnetic agitation and liquid sampling. Typically, the vessel was charged with $0.25 \mathrm{~L}$ of MTP solution $\left(50 \mathrm{mg} \mathrm{L}^{-1}\right)$ prepared in ultrapure water (Milli-Q) at $\mathrm{pH} 7$ and $0.2 \mathrm{~g} \mathrm{~L}^{-1}$ of MBC. The suspension was stirred for 30 min for homogenization and MTP adsorption purposes. Then, the reactor vessel was placed in the solar box described above and the required amount of $\mathrm{H}_{2} \mathrm{O}_{2}$ was added. Immediately, the lamp was turned on if illumination was required. Samples were periodically withdrawn from the reactor, filtered through $0.45 \mu \mathrm{m}$ PET membranes, and analyzed for $\mathrm{MTP}, \mathrm{pH}$, $\mathrm{H}_{2} \mathrm{O}_{2}$, TOC, $\mathrm{H}_{2} \mathrm{BDC}$, and dissolved iron. Aliquots of selected samples were analyzed for total iron (non-filtered samples) after separating the catalyst particles with a magnet. The reutilization of the $\mathrm{Fe}_{3} \mathrm{O}_{4}$-AC sample was studied by performing nine consecutive runs under illumination. At the end of each run, the catalyst was separated magnetically with an external magnet and used without further treatment in the next cycle with a fresh MTP solution.

\subsection{Analytical Methods for Reaction Monitoring}

Total iron concentration was evaluated spectrophotometrically at $565 \mathrm{~nm}$ by Spectroquant ${ }^{\circledR}$ iron test (Merck 1.14761.0001). Measurements of $\mathrm{pH}$ were taken with a $\mathrm{pH}$-meter (Crison GLP21+). Hydrogen peroxide in liquid samples was also measured using the method 
proposed by Eisenberg [66]. All the spectrophotometric measurements were carried out on a Helios $\alpha$ spectrophotometer from Thermo Spectronic using $1 \mathrm{~cm}$ path length cuvettes. TOC was determined on filtered samples using a Shimadzu apparatus (TOC-V CSH model). $\mathrm{H}_{2} \mathrm{BDC}$ and MTP concentrations were analyzed by a gradient method on a HPLC apparatus provided with a UV-Vis detector set at $225 \mathrm{~nm}$ (HP 1100 Series chromatograph, Agilent Technologies, Santa Clara, CA, USA). A Kromasil C-18 column ( $5 \mu \mathrm{m}, 150 \mathrm{~mm}$ length, $4 \mathrm{~mm}$ diameter) was used as stationary phase while the mobile phase consisted of a mixture of $0.1 \%$ vol. o-phosphoric acid in ultrapure water (solvent A) and acetonitrile (solvent B) at a constant flowrate of $1 \mathrm{~mL} \mathrm{~min}^{-1}$. The mobile phase program used for the analysis was as follows: start at 20\% B; 0-6 min, linear gradient of B in A (20-27.5\% B); 6-7 min, hold at $27.5 \% \mathrm{~B}, 7-8 \mathrm{~min}$, linear gradient $(27.5-20 \% \mathrm{~B}) ; 8-9 \mathrm{~min}$, hold at $20 \% \mathrm{~B}$. The retention times were $3.4 \mathrm{~min}\left(\mathrm{H}_{2} \mathrm{BDC}\right)$ and $4.1 \mathrm{~min}(\mathrm{MTP})$.

\section{Conclusions}

The synthesis method proposed in this work allowed obtaining mesoporous magnetite and magnetized carbonaceous materials of high purity, with excellent magnetic properties that facilitate their separation, and acceptable textural properties for their possible application as catalysts in different processes. The method proved to be easily scalable, possible to carry out at ambient conditions, and have a high percentage recovery of one of the main reagents (i.e., terephthalic acid), which can be reused into a new synthesis, thus falling within the philosophy of green synthesis to obtain environmentally friendly materials.

The materials thus obtained, bare magnetite and three carbonaceous composites (prepared from activated carbon, graphene and graphene oxide), were active for photoCWPO, as demonstrated treating an aqueous solution of MTP. $\mathrm{Fe}_{3} \mathrm{O}_{4}-\mathrm{G}$ and $\mathrm{Fe}_{3} \mathrm{O}_{4}-\mathrm{GO}$ showed low stability compared with $\mathrm{Fe}_{3} \mathrm{O}_{4}$ and $\mathrm{Fe}_{3} \mathrm{O}_{4}$-AC. Moreover, the latter presented catalytic activity much superior to bare $\mathrm{Fe}_{3} \mathrm{O}_{4}$. MTP and TOC conversions higher than $90 \%$ and $20 \%$, respectively, were achieved after $3 \mathrm{~h}$ of treatment with $\mathrm{Fe}_{3} \mathrm{O}_{4}-\mathrm{AC}$ at initial aqueous $\mathrm{pH} 7$ ( $\mathrm{pH}$ dropped to c.a 4). At circumneutral $\mathrm{pH}$ ( $\mathrm{pH}$ was controlled at about 7 throughout the process) MTP removal was still moderate $(>60 \%)$, this being a typical limiting issue in photo-Fenton treatments. The best efficiency in the use of $\mathrm{H}_{2} \mathrm{O}_{2}$ was $0.23 \mathrm{~mol} \mathrm{C}$ eliminated per mol $\mathrm{H}_{2} \mathrm{O}_{2}$ consumed, which is about a $60 \%$ of the maximum attainable efficiency. $\mathrm{Fe}_{3} \mathrm{O}_{4}$-AC could be easily reused in a nine-consecutive CWPO experiment recovering the catalyst with a magnet after each cycle. Moderate catalyst deactivation was observed mainly due to the blockage of some micropores and/or loss of $\mathrm{Fe}^{2+}$ catalytic sites. Nevertheless, deactivation from the fourth cycle onwards was negligible and magnetic separability remained quite satisfactory.

Author Contributions: Conceptualization, P.M.Á. and A.R.; methodology, J.L.; validation, J.F.G.-A.; investigation, J.L., A.R., J.F.G.-A. and P.M.Á.; data curation, J.L.; writing-original draft preparation, J.L. and A.R.; writing - review and editing, A.R. and P.M.Á.; supervision, P.M.Á.; project administration, P.M.Á.; funding acquisition, P.M.Á. and J.F.G.-A. All authors have read and agreed to the published version of the manuscript.

Funding: This research was funded by the Junta de Extremadura (GR18014-Reserch Group) and the Agencia Estatal de Investigación (AEI) of Spain through the project PID2019-104429RB-I00/AEI/10.130 39/501100011033, co-financed by the European Funds for Regional Development (FEDER, UE).

Acknowledgments: The authors thank the SAIUEX service of the University of Extremadura for the characterization analyses. Jorge López Gallego is also grateful to the Ministerio de Educación, Cultura y Deporte of Spain for a FPU grant (reference number FPU16/03629).

Conflicts of Interest: The authors declare no conflict of interest. 


\section{References}

1. Arias, L.S.; Pessan, J.P.; Vieira, A.P.M.; De Lima, T.M.T.; Delbem, A.C.B.; Monteiro, D.R. Iron Oxide Nanoparticles for Biomedical Applications: A Perspective on Synthesis, Drugs, Antimicrobial Activity, and Toxicity. Antibiotics 2018, 7, 46. [CrossRef] [PubMed]

2. Gupta, A.K.; Gupta, M. Synthesis and Surface Engineering of Iron Oxide Nanoparticles for Biomedical Applications. Biomaterials 2005, 26, 3995-4021. [CrossRef] [PubMed]

3. Cotin, G.; Piant, S.; Mertz, D.; Felder-Flesch, D.; Begin-Colin, S. Iron Oxide Nanoparticles for Biomedical Applications: Synthesis, Functionalization, and Application; Elsevier Ltd.: Amsterdam, The Netherlands, 2018. [CrossRef]

4. Nasir Baig, R.B.; Verma, S.; Nadagoud, M.N.; Varma, R.S. Advancing Sustainable Catalysis with Magnetite. Surface Modification and Synthetic Applications. Aldrichimica Acta 2016, 49, 35-41.

5. Masudi, A.; Harimisa, G.E.; Ghafar, N.A.; Jusoh, N.W.C. Magnetite-Based Catalysts for Wastewater Treatment. Environ. Sci. Pollut. Res. 2020, 27, 4664-4682. [CrossRef]

6. Muñoz, M.; de Pedro, Z.M.; Casas, J.A.; Rodríguez, J.J. Preparation of Magnetite-Based Catalysts and Their Application in Heterogeneous Fenton Oxidation-A Review. Appl. Catal. B Environ. 2015, 176-177, 249-265. [CrossRef]

7. Thomas, N.; Dionysiou, D.D.; Pillai, S.C. Heterogeneous Fenton Catalysts: A Review of Recent Advances. J. Hazard. Mater. 2021, 404, 124082. [CrossRef] [PubMed]

8. Ribeiro, R.S.; Silva, A.M.T.; Figueiredo, J.L.; Faria, J.L.; Gomes, H.T. Catalytic Wet Peroxide Oxidation: A Route towards the Application of Hybrid Magnetic Carbon Nanocomposites for the Degradation of Organic Pollutants. A Review. Appl. Catal. B Environ. 2016, 187, 428-460. [CrossRef]

9. Lai, L.; He, Y.; Zhou, H.; Huang, B.; Yao, G.; Lai, B. Critical Review of Natural Iron-Based Minerals Used as Heterogeneous Catalysts in Peroxide Activation Processes: Characteristics, Applications and Mechanisms. J. Hazard. Mater. 2021, 416, 125809. [CrossRef] [PubMed]

10. Teja, A.S.; Koh, P.Y. Synthesis, Properties, and Applications of Magnetic Iron Oxide Nanoparticles. Prog. Cryst. Growth Charact. Mater. 2009, 55, 22-45. [CrossRef]

11. Zhang, Z.J.; Chen, X.Y.; Wang, B.N.; Shi, C.W. Hydrothermal Synthesis and Self-Assembly of Magnetite $\left(\mathrm{Fe}_{3} \mathrm{O}_{4}\right) \mathrm{Nanoparticles}$ with the Magnetic and Electrochemical Properties. J. Cryst. Growth 2008, 310, 5453-5457. [CrossRef]

12. Nidheesh, P.V. Heterogeneous Fenton Catalysts for the Abatement of Organic Pollutants from Aqueous Solution: A Review. RSC Adv. 2015, 5, 40552-40577. [CrossRef]

13. Peng, S.; Wang, C.; Xie, J.; Sun, S. Synthesis and Stabilization of Monodisperse Fe Nanoparticles. J. Am. Chem. Soc. 2006, 128, 10676-10677. [CrossRef] [PubMed]

14. Ge, J.; Hu, Y.; Biasini, M.; Dong, C.; Guo, J.; Beyermann, W.P.; Yin, Y. One-Step Synthesis of Highly Water-Soluble Magnetite Colloidal Nanocrystals. Chem.A Eur. J. 2007, 13, 7153-7161. [CrossRef] [PubMed]

15. Li, Z.; Chen, H.; Bao, H.; Gao, M. One-Pot Reaction to Synthesize Water-Soluble Magnetite Nanocrystals. Chem. Mater. 2004, 16, 1391-1393. [CrossRef]

16. Lu, X.; Niu, M.; Qiao, R.; Gao, M. Superdispersible PVP-Coated $\mathrm{Fe}_{3} \mathrm{O}_{4}$ Nanocrystals Prepared by a “One-Pot” Reaction. J. Phys. Chem. B 2008, 112, 14390-14394. [CrossRef] [PubMed]

17. Mizukoshi, Y.; Shuto, T.; Masahashi, N.; Tanabe, S. Preparation of Superparamagnetic Magnetite Nanoparticles by Reverse Precipitation Method: Contribution of Sonochemically Generated Oxidants. Ultrason. Sonochem. 2009, 16, 525-531. [CrossRef]

18. Nedkov, I.; Merodiiska, T.; Slavov, L.; Vandenberghe, R.E.; Kusano, Y.; Takada, J. Surface Oxidation, Size and Shape of Nano-Sized Magnetite Obtained by Co-Precipitation. J. Magn. Magn. Mater. 2006, 300, 358-367. [CrossRef]

19. Qu, S.; Yang, H.; Ren, D.; Kan, S.; Zou, G.; Li, D.; Li, M. Magnetite Nanoparticles Prepared by Precipitation from Partially Reduced Ferric Chloride Aqueous Solutions. J. Colloid Interface Sci. 1999, 215, 190-192. [CrossRef] [PubMed]

20. Ozkaya, T.; Toprak, M.S.; Baykal, A.; Kavas, H.; Köseoğlu, Y.; Aktaş, B. Synthesis of $\mathrm{Fe}_{3} \mathrm{O}_{4}$ Nanoparticles at $100{ }^{\circ} \mathrm{C}$ and Its Magnetic Characterization. J. Alloys Compd. 2009, 472, 18-23. [CrossRef]

21. Kobyliukh, A.; Olszowska, K.; Godzierz, M.; Kordyka, A.; Kubacki, J.; Mamunya, Y.; Pusz, S.; Stoycheva, I.; Szeluga, U. Effect of Graphene Material Structure and Iron Oxides Deposition Method on Morphology and Properties of Graphene/Iron Oxide Hybrids. Appl. Surf. Sci. 2022, 573, 151567. [CrossRef]

22. Ioffe, M.; Long, M.; Radian, A. Systematic Evaluation of Activated Carbon- $\mathrm{Fe}_{3} \mathrm{O}_{4}$ Composites for Removing and Degrading Emerging Organic Pollutants. Environ. Res. 2021, 198, 111187. [CrossRef]

23. Lopes, K.L.; de Oliveira, H.L.; Serpa, J.A.S.; Torres, J.A.; Nogueira, F.G.E.; de Freitas, V.A.A.; Borges, K.B.; Silva, M.C. Nanomagnets Based on Activated Carbon/Magnetite Nanocomposite for Determination of Endocrine Disruptors in Environmental Water Samples. Microchem. J. 2021, 168, 106366. [CrossRef]

24. Rodríguez-Sánchez, S.; Ruíz, B.; Martínez-Blanco, D.; Sánchez-Arenillas, M.; Díez, M.A.; Marco, J.F.; Gorria, P.; Fuente, E. Towards Advanced Industrial Waste-Based Magnetic Activated Carbons with Tunable Chemical, Textural and Magnetic Properties. Appl. Surf. Sci. 2021, 551, 149407. [CrossRef]

25. Stan, M.; Lung, I.; Soran, M.L.; Leostean, C.; Popa, A.; Stefan, M.; Lazar, M.D.; Opris, O.; Silipas, T.D.; Porav, A.S. Removal of Antibiotics from Aqueous Solutions by Green Synthesized Magnetite Nanoparticles with Selected Agro-Waste Extracts. Process Saf. Environ. Prot. 2017, 107, 357-372. [CrossRef] 
26. Jiang, Y.; Wang, W.N.; Biswas, P.; Fortner, J.D. Facile Aerosol Synthesis and Characterization of Ternary Crumpled Graphene$\mathrm{TiO}_{2}$-Magnetite Nanocomposites for Advanced Water Treatment. ACS Appl. Mater. Interfaces 2014, 6, 11766-11774. [CrossRef] [PubMed]

27. Kim, S.E.; Kim, K.W.; Lee, S.W.; Kim, S.O.; Kim, J.S.; Lee, J.K. Synthesis and Characterization of TiO 2 -Coated Magnetite Clusters $\left(\mathrm{NFe}_{3} \mathrm{O}_{4} @ \mathrm{TiO}_{2}\right)$ as Anode Materials for Li-Ion Batteries. Curr. Appl. Phys. 2013, 13, 1923-1927. [CrossRef]

28. Dimiev, A.M.; Alemany, L.B.; Tour, J.M. Graphene Oxide. Origin of Acidity, Its Instability in Water, and a New Dynamic Structural Model. ACS Nano 2013, 7, 576-588. [CrossRef]

29. Cabrera-Munguia, D.A.; León-Campos, M.I.; Claudio-Rizo, J.A.; Solís-Casados, D.A.; Flores-Guia, T.E.; Cano Salazar, L.F. Potential Biomedical Application of a New MOF Based on a Derived PET: Synthesis and Characterization. Bull. Mater. Sci. 2021, $44,245$. [CrossRef]

30. Cosimbescu, L.; Merkel, D.R.; Darsell, J.; Petrossian, G. Simple but Tricky: Investigations of Terephthalic Acid Purity Obtained from Mixed PET Waste. Ind. Eng. Chem. Res. 2021, 60, 12792-12797. [CrossRef]

31. Varaprasad, K.; Pariguana, M.; Raghavendra, G.M.; Jayaramudu, T.; Sadiku, E.R. Development of Biodegradable Metalox-

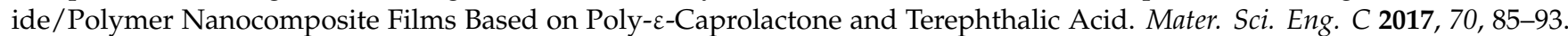
[CrossRef]

32. Ball, G.L.; McLellan, C.J.; Bhat, V.S. Toxicological Review and Oral Risk Assessment of Terephthalic Acid (TPA) and Its Esters: A Category Approach. Crit. Rev. Toxicol. 2011, 42, 28-67. [CrossRef] [PubMed]

33. Hoshi, A.; Yanai, R.; Kuretani, K. Toxicity of Terephthalic Acid. Chem. Pharm. Bull. 1968, 16, 1655-1660. [CrossRef]

34. Zhang, X.X.; Sun, S.L.; Zhang, Y.; Wu, B.; Zhang, Z.Y.; Liu, B.; Yang, L.Y.; Cheng, S.P. Toxicity of Purified Terephthalic Acid Manufacturing Wastewater on Reproductive System of Male Mice (Mus Musculus). J. Hazard. Mater. 2010, 176, $300-305$. [CrossRef]

35. Wang, D.; Yang, P.; Zhu, Y. Growth of $\mathrm{Fe}_{3} \mathrm{O}_{4}$ Nanoparticles with Tunable Sizes and Morphologies Using Organic Amine. Mater. Res. Bull. 2014, 49, 514-520. [CrossRef]

36. Kumar, S.R.; Raja, M.M.; Mangalaraj, D.; Viswanathan, C.; Ponpandian, N. Surfactant Free Solvothermal Synthesis of Monodispersed 3D Hierarchical $\mathrm{Fe}_{3} \mathrm{O}_{4}$ Microspheres. Mater. Lett. 2013, 110, 98-101. [CrossRef]

37. Li, Y.; Jiang, R.; Liu, T.; Lv, H.; Zhou, L.; Zhang, X. One-Pot Synthesis of Grass-like $\mathrm{Fe}_{3} \mathrm{O}_{4}$ Nanostructures by a Novel Microemulsion-Assisted Solvothermal Method. Ceram. Int. 2014, 40 Pt A, 1059-1063. [CrossRef]

38. Haw, C.Y.; Mohamed, F.; Chia, C.H.; Radiman, S.; Zakaria, S.; Huang, N.M.; Lim, H.N. Hydrothermal Synthesis of Magnetite Nanoparticles as MRI Contrast Agents. Ceram. Int. 2010, 4, 1417-1422. [CrossRef]

39. Figueiredo, J.L.; Pereira, M.F.R.; Freitas, M.M.A.; Órfão, J.J.M. Modification of the Surface Chemistry of Activated Carbons. Carbon N. Y. 1999, 37, 1379-1389. [CrossRef]

40. Pastrana-Martínez, L.M.; Morales-Torres, S.; Likodimos, V.; Falaras, P.; Figueiredo, J.L.; Faria, J.L.; Silva, A.M.T. Role of Oxygen Functionalities on the Synthesis of Photocatalytically Active Graphene- $\mathrm{TiO}_{2}$ Composites. Appl. Catal. B Environ. 2014, 158-159, 329-340. [CrossRef]

41. Ruíz-Baltazar, A.; Esparza, R.; Rosas, G.; Pérez, R. Effect of the Surfactant on the Growth and Oxidation of Iron Nanoparticles. J Nanomater. 2015, 2015, 240948. [CrossRef]

42. Pop, D.; Buzatu, R.; Moacă, E.A.; Watz, C.G.; Cîntă-Pînzaru, S.; Tudoran, L.B.; Nekvapil, F.; Avram, S.; Dehelean, C.A.; Crețu, M.O.; et al. Development and Characterization of $\mathrm{Fe}_{3} \mathrm{O}_{4} @$ Carbon Nanoparticles and Their Biological Screening Related to Oral Administration. Materials 2021, 14, 3556. [CrossRef]

43. Daou, T.J.; Grenèche, J.M.; Pourroy, G.; Buathong, S.; Derory, A.; Ulhaq-Bouillet, C.; Donnio, B.; Guillon, D.; Begin-Colin, S. Coupling Agent Effect on Magnetic Properties of Functionalized Magnetite-Based Nanoparticles. Chem. Mater. 2008, 20, 5869-5875. [CrossRef]

44. Rizzuti, A.; Dassisti, M.; Mastrorilli, P.; Sportelli, M.C.; Cioffi, N.; Picca, R.A.; Agostinelli, E.; Varvaro, G.; Caliandro, R. ShapeControl by Microwave-Assisted Hydrothermal Method for the Synthesis of Magnetite Nanoparticles Using Organic Additives. J. Nanopart. Res. 2015, 17, 408. [CrossRef]

45. Niemeyer, J.; Chen, Y.; Bollag, J.-M. Characterization of Humic Acids, Composts, and Peat by Diffuse Reflectance FourierTransform Infrared Spectroscopy. Soil Sci. Soc. Am. J. 1992, 56, 135. [CrossRef]

46. Moreno-Castilla, C.; López-Ramón, M.V.; Carrasco-Marín, F. Changes in Surface Chemistry of Activated Carbons by Wet Oxidation. Carbon N. Y. 2000, 38, 1995-2001. [CrossRef]

47. Pakuła, M.; Świątkowski, A.; Walczyk, M.; Biniak, S. Voltammetric and FT-IR Studies of Modified Activated Carbon Systems with Phenol, 4-Chlorophenol or 1,4-Benzoquinone Adsorbed from Aqueous Electrolyte Solutions. Colloids Surf. A Physicochem. Eng. Asp. 2005, 260, 145-155. [CrossRef]

48. Komarneni, S.; Hu, W.; Noh, Y.D.; Van Orden, A.; Feng, S.; Wei, C.; Pang, H.; Gao, F.; Lu, Q.; Katsuki, H. Magnetite Syntheses from Room Temperature to $150{ }^{\circ} \mathrm{C}$ with and without Microwaves. Ceram. Int. 2012, 38, 2563-2568. [CrossRef]

49. Mascolo, M.C.; Pei, Y.; Ring, T.A. Room Temperature Co-Precipitation Synthesis of Magnetite Nanoparticles in a Large Ph Window with Different Bases. Materials 2013, 6, 5549-5567. [CrossRef]

50. Iano ${ }^{\text {s }}$, R.; Păcurariu, C.; Mihoc, G. Magnetite/Carbon Nanocomposites Prepared by an Innovative Combustion Synthesis Technique-Excellent Adsorbent Materials. Ceram. Int. 2014, 40 Pt B, 13649-13657. [CrossRef] 
51. He, Y.T.; Traina, S.J. Transformation of Magnetite to Goethite under Alkaline pH Conditions. Clay Miner. 2007, 42, 13-19. [CrossRef]

52. López, J.; Chávez, A.M.; Rey, A.; Álvarez, P.M. Insights into the Stability and Activity of MIL-53(Fe) in Solar Photocatalytic Oxidation Processes in Water. Catalysts 2021, 11, 448. [CrossRef]

53. Sun, H.; Xie, G.; He, D.; Zhang, L. Ascorbic Acid Promoted Magnetite Fenton Degradation of Alachlor: Mechanistic Insights and Kinetic Modeling. Appl. Catal. B Environ. 2020, 267, 118383. [CrossRef]

54. Carbajo, J.; Quintanilla, A.; Garcia-Costa, A.L.; González-Julián, J.; Belmonte, M.; Miranzo, P.; Osendi, M.I.; Casas, J.A. The Influence of the Catalyst on the CO Formation during Catalytic Wet Peroxide Oxidation Process. Catal. Today 2021, 361, 30-36. [CrossRef]

55. Rey, A.; Quiñones, D.H.; Álvarez, P.M.; Beltrán, F.J.; Plucinski, P.K. Simulated Solar-Light Assisted Photocatalytic Ozonation of Metoprolol over Titania-Coated Magnetic Activated Carbon. Appl. Catal. B Environ. 2012, 111-112, 246-253. [CrossRef]

56. Quiñones, D.H.; Rey, A.; Álvarez, P.M.; Beltrán, F.J.; Plucinski, P.K. Enhanced Activity and Reusability of TiO 2 Loaded Magnetic Activated Carbon for Solar Photocatalytic Ozonation. Appl. Catal. B Environ. 2014, 144, 96-106. [CrossRef]

57. Pliego, G.; Garcia-Muñoz, P.; Zazo, J.A.; Casas, J.A.; Rodriguez, J.J. Improving the Fenton Process by Visible LED Irradiation. Environ. Sci. Pollut. Res. 2016, 23, 23449-23455. [CrossRef]

58. García-Muñoz, P.; Zussblatt, N.P.; Pliego, G.; Zazo, J.A.; Fresno, F.; Chmelka, B.F.; Casas, J.A. Evaluation of Photoassisted Treatments for Norfloxacin Removal in Water Using Mesoporous $\mathrm{Fe}_{2} \mathrm{O}_{3}-\mathrm{TiO}_{2}$ Materials. J. Environ. Manag. 2019, 238, $243-250$. [CrossRef]

59. Oller, I.; Malato, S. Photo-Fenton Applied to the Removal of Pharmaceutical and Other Pollutants of Emerging Concern. Curr. Opin. Green Sustain. Chem. 2021, 29, 100458. [CrossRef]

60. Domínguez, C.M.; Ocón, P.; Quintanilla, A.; Casas, J.A.; Rodriguez, J.J. Highly Efficient Application of Activated Carbon as Catalyst for Wet Peroxide Oxidation. Appl. Catal. B Environ. 2013, 140-141, 663-670. [CrossRef]

61. Rey, A.; Hungria, A.B.; Duran-Valle, C.J.; Faraldos, M.; Bahamonde, A.; Casas, J.A.; Rodriguez, J.J. On the Optimization of Activated Carbon-Supported Iron Catalysts in Catalytic Wet Peroxide Oxidation Process. Appl. Catal. B Environ. 2016, 181, 249-259. [CrossRef]

62. Rey, A.; Bahamonde, A.; Casas, J.A.; Rodríguez, J.J. Selectivity of Hydrogen Peroxide Decomposition towards Hydroxyl Radicals in Catalytic Wet Peroxide Oxidation (CWPO) over Fe/AC Catalysts. Water Sci. Technol. 2010, 61, 2769-2778. [CrossRef] [PubMed]

63. Maity, D.; Choo, S.G.; Yi, J.; Ding, J.; Xue, J.M. Synthesis of magnetite nanoparticles via a solvent-free thermal decomposition route. J. Magn. Magn. Mater. 2009, 321, 1256-1259. [CrossRef]

64. Grosvenor, A.P.; Kobe, B.A.; Biesinger, M.C.; Mcintyre, N.S. Investigation of multiplet splitting of Fe 2p XPS spectra and bonding in iron compounds. Surf. Interface Anal. 2004, 36, 1564-1574. [CrossRef]

65. Chávez, A.M.; Rey, A.; Beltrán, F.J.; Álvarez, P.M. Solar Photo-Ozonation: A Novel Treatment Method for the Degradation of Water Pollutants. J. Hazard. Mater. 2016, 317, 36-43. [CrossRef] [PubMed]

66. Eisenberg, G.M. Colorimetric Determination of Hydrogen Peroxide. Ind. Eng. Chem.-Anal. Ed. 1943, 15, 327-328. [CrossRef] 